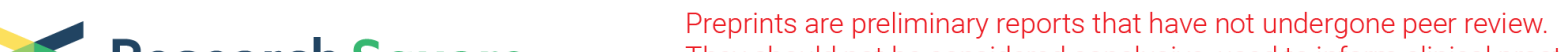 $\begin{array}{ll}\text { Research Square } & \text { They should not be considered conclusive, used to inform clinical practice, } \\ \text { or referenced by the media as validated information. }\end{array}$
}

\section{Research on Seismic Dynamic Response Characteristics of Weak Surrounding Rock Slope With Double-Arch Tunnel}

\section{Xueliang Jiang}

Central South University of Forestry and Technology

\section{Yonghui Qian ( $1184435614 @ q q . c o m$ )}

Central South University of Forestry and Technology https://orcid.org/0000-0003-0003-916X

\section{Jiqi Zhang}

Central South University of Forestry and Technology

\section{Yong Liu}

Guangdong Zhongye Shanhe Construction Engineering CO

\section{RiWe Deng}

Guangdong Zhongye Shanhe Construction Engineer Co

\section{Li Huang}

Guangdong Zhongye Shanhe Construction Engineering CO

\section{GuoJie Lai}

Guangdong Zhongye Shanhe Construction Engineering CO

\section{Research Article}

Keywords: earthquake engineering, seismic dynamic characteristics, large shaking table model test, slope with double-arch tunnel, acceleration response, dynamic displacement response.

Posted Date: June 1st, 2021

DOl: https://doi.org/10.21203/rs.3.rs-517421/v1

License: (a) (1) This work is licensed under a Creative Commons Attribution 4.0 International License. Read Full License 


\section{Abstract}

Through the shaking table test, Wenchuan wave (WC) was used as the excitation wave of the shaking table test. The vibration was excited in three directions: horizontal (x), vertical (z), and horizontal and vertical (xz) and the dynamic response characteristics of rock slopes was studied. The results show:(1) The acceleration amplification factor of each measuring point of the slope shows a nonlinear increasing trend with the increase of the slope height.The slope changes the frequency spectrum of the loaded seismic wave.The slope has a filtering effect on the high frequency band of the seismic wave.(2) Under the unidirectional cyclic loading of Wenchuan wave, the slope acceleration amplification factor increases with the increase of the peak value of the seismic wave. Under the bi-directional excitation of Wenchuan wave, the slope acceleration amplification coefficient generally decreases with the increase of the peak value of the seismic wave.The slope acceleration amplification factor presents the characteristics of first increasing and then decreasing with the increase of the relative height of the slope.(3) The dynamic displacement response characteristics of the tunnel slope with double-arch tunnel are mainly affected by the seismic wave in the same direction and the peak value of the dynamic displacement response increases with the increase of the seismic wave peak value.(4) The peak dynamic displacement response of the double-arch tunnel slope shows a non-linear change trend with the increase of slope height. The dynamic displacement peak growth rate is slower below the rock interface and the dynamic displacement peak increases rapidly above the interface and Maximum displacement occurred at the top of the slope.

\section{Introduction}

China is a mountainous country that is severely affected by earthquake disasters. In the Wenchuan earthquake, a large number of slopes were damaged and the dynamic response characteristics and stability of slopes under the action of the earthquake have received increasing attention. Since the reform and opening up, my country's infrastructure construction has developed rapidly.A large number of tunnels have been built and some of which are restricted by factors such as land restrictions, complex mountain topography, and highway orientation. As one of the tunnel types, the double-arch tunnel has the advantages of large passage area and small land area. Therefore, it has obvious advantages in the situations of tight urban land, complex geological conditions in mountainous areas, and difficulty in line design. Such as Yunnan Yuanmo Expressway Xiaomansa River Tunnel(2006), Ningqi Expressway Huishuihe No. 4 double-arch tunnel 2009 \. my country is located at the junction of the Pacific plate and the Indian Ocean plate, and the seismic zones are widely distributed. Therefore, the dynamic response and stability of the slope of the double-arch tunnel under the action of earthquake have become an urgent problem to be solved.

At present, the research on slope stability under static force has made rich research results(2016 and 2015). Compared with these achievements, the research results of slope stability under seismic dynamic action are relatively few(2003).Shaking table test can reproduce seismic action more realistically, and it has become an important method for many scholars to study the dynamic response of slopes to earthquakes. Liu et al. used shaking table model tests to study the dynamic response(2018), slope 
deformation and stability coefficient variation characteristics and failure modes of bedding rock slopes with different inclination angles under frequent small earthquakes. Yang et al. studied the dynamic stability of the slope supported by the lattice anchor frame by shaking table tests(2012), and revealed the influence of different excitation directions on the dynamic response characteristics of the slope supported by the lattice anchor frame. M. L. Lin and K.L. Wang used shaking table tests to study the stability of sand slopes under earthquake action(2006), explored the factors affecting slope deformation, and revealed the shape of the slope failure surface. Yang et al. used large-scale shaking table model tests to explore the dynamic acceleration response characteristics of bedding and homogeneous structure rock slopes and the influence of power input parameters on the dynamic characteristics of the slope(2012). Ye et al. used the shaking table test to gradually increase the peak value of the seismic wave until the slope was damaged, and proved the dynamic characteristics of the slope failure(2012). Yang et al. carried out a slope shaking table test, studied the seismic landslide response of single and double-sided high-steep rock slopes(2013), and revealed the similarities and differences in the seismic dynamic response of single- and double-sided high-steep slopes. Xu et al. used large-scale shaking table tests to reveal the dynamic characteristics of slopes under earthquake dynamics and the influence of ground motion parameters on the dynamic response characteristics of slopes(2008). In summary, relying on the shaking table test to carry out the study of the seismic dynamic characteristics of the slope has achieved a lot of results, but for the slope containing the tunnel, the results of using the shaking table test to study the seismic response characteristics are few. Niu et al. carried out shaking table model tests on rock slopes containing tunnels(2018,2018 and 2017), and established dynamic numerical analysis models of slopes through finite element analysis software. The dynamic response law under the action of earthquake was studied, and the influence of the tunnel structure on the dynamic response characteristics of the slope was discussed. Jiang et al. discussed the acceleration and dynamic displacement response of the horizontal layered rock slope of the underlying tunnel and the influence of ground motion parameters on the dynamic response characteristics of the slope, and revealed the rock quality of the tunnel with small clear distance (2018 and 2017). The acceleration and dynamic displacement response characteristics of the slope under the action of earthquake. Chen and Lin calculated the slope safety factor and researched the consistency analysis of Hoek-Brown and equivalent Mohr-Coulomb parameters(2019). At present, the study on the slope stability of tunnels with double-arch tunnel using shaking table tests has not been found in the literature. The occurrence environment of the slope of the tunnel with multiple arches is obviously different from that of the ordinary slope. The existence of the double-arch tunnel deteriorates the mechanical environment of the slope, increases the uncertainty of the seismic wave action in the slope, and its response law and damage under earthquake action. In this paper, a model of the slope of a double-arch tunnel was designed with a scale of 1:20 and a large-scale shaking table test was carried out to study the acceleration and dynamic displacement response characteristics of the slope.

\section{Test Scheme}

\subsection{Test instruments and equipment}


The model test was completed in the shaking table system of Central South University. The vibration table could move in three directions and six degrees of freedom;the load could reach 30t.the table size is $4 \mathrm{~m} \times 4 \mathrm{~m}$ and the working frequency range was $0.1 \mathrm{~Hz} \sim 50 \mathrm{~Hz}$. the maximum dynamic displacement in $X$ and $Y$ directions is $250 \mathrm{~mm}$, and the full load acceleration was both $\pm 1.0 \mathrm{~g}$.the maximum dynamic displacement in the $Z$ direction was $160 \mathrm{~mm}$, and the full load acceleration was $\pm 1.6 \mathrm{~g}$. The shaking table is shown in Fig. 1.

\subsection{Similarity relation design}

When deriving the similarity relationship in the model test, three similar theorems should be followed, namely the first similarity theorem, the similar second theorem, and the similar third theorem. In the design and production process of the slope model(1998), it is necessary to select a reasonable similarity law so that the model test can correctly reflect the seismic dynamic behavior of the prototype. Due to the influence of factors such as the size and size effect of the vibrating table, the maximum vibration speed, and material parameters, it is difficult to satisfy all the similar relationships between the model and the prototype. Therefore, according to the primary problem and purpose of the research, grasp the main similarity conditions, ignore the secondary similarity conditions, and adopt approximate modeling methods for design. And considering the influence of test conditions, material parameters, boundary conditions and other factors, determine the similarity ratio of the three basic dimensions. Their similarity ratios are: geometric similarity ratio $C_{l}=1: 20$, density similarity ratio $C_{p}=1: 1$, acceleration similarity ratio $C_{a}=1: 1$, and other main similarity constants are derived based on the similarity theory. The specific parameters are shown in Table 1.

\subsection{Fabrication of similar materials}

The model test was $70 \mathrm{~m} \times 42 \mathrm{~m} \times 30 \mathrm{~m}$ (length $\times$ height $\times$ width) and based on a multi-arch tunnel of a southern expressway crossing a mountain. Among them, the slope was $45^{\circ}$, and the length of the trailing edge of the slope top was $36 \mathrm{~m}$. The overlying rock layer was a layered rock layer, the upper rock layer was a type V surrounding rock, the middle was a type IV surrounding rock, and the lower rock was a type III bedrock. The tunnel passed through the upper and middle rock formations. The experiment used medium-coarse sand as the coarse aggregate to make concrete. Through the ratio test, it was determined that the concrete with the ratio of 1:7.83:1.46 (cement: sand: water) was used as the material for the lining of the double-arch tunnel. The thickness of the lining was $3 \mathrm{~cm}$, and the galvanized wire mesh with a diameter of $2 \mathrm{~mm}$ and a spacing of $1 \mathrm{~cm}$ was used in the lining to simulate the steel wire mesh in the actual lining. The lining model was shown in Fig. 2 below. The base of the model was made of cement mortar with a ratio of 1:8.13:1.51 and M2.5, with a thickness of $10 \mathrm{~cm}$. The slope in the test model used barite powder and silty clay to simulate two different types of weak surrounding rocks through different proportions. The test simulated the weak and weak surrounding rocks of grade IV and V. According to the principle of material similarity, the mass ratio of the lower surrounding rock is 10:5:1 (barite powder: quartz sand: lithium-based lubricant), which simulates grade IV surrounding rock. The upper surrounding rock was made of sand-bearing silty clay to simulate Class $V$ surrounding rock. The prototype material 
parameters are shown in Table 2, and the basic parameters of the model test materials are shown in Table 3.

\subsection{Design of model box and test boundary conditions}

The test used a rigid model box, which was an important equipment for the test. Its internal net size is $150 \times 350 \times 210$ (width $\times$ length $\times$ height, unit: $\mathrm{cm}$ ), and transparent plexiglass panels was installed on both sides of the inner side of the model box. Due to the constraint effect of the model box and the model box effect (2000), the internal boundary of the model box must be processed to reduce the influence of the boundary on the model slope. Lay a layer of $4 \mathrm{~cm}$ thick gravel on the bottom of the model box to increase the friction, and fill the pores of the gravel with fine sand and smooth it as the friction boundary. A foam board with a thickness of $10 \mathrm{~cm}$ was pasted on the inner wall of the back side of the model box as a flexible boundary. The inner walls of both sides was pasted with foam boards of the same thickness and a layer of polyvinyl chloride plastic film was pasted on the surface as a sliding boundary. The internal boundary processing of the model box is shown in Fig. 3.

\subsection{Sensor layout plan}

On the central axis of the model slope surface, 10 displacement sensors was arranged. Among them, 5 displacement sensors was arranged parallel to the $x$ direction of the horizontal excitation direction, numbered DX1 DX5, to measure the dynamic displacement of the slope in the horizontal $x$ direction. Five displacement sensors, numbered DZ10DZ5, was also arranged in the z direction parallel to the vertical excitation direction to measure the dynamic displacement of the slope in the vertical $z$ direction. Acceleration sensors in the $x$ and $z$ directions was arranged at each intersection of the horizontal line and the slope where the displacement measuring points was located. There was 5 sensors in the horizontal direction, which measured the acceleration in the horizontal $x$ direction, numbered AX1ロAX5; the 5 sensors in the vertical direction, which measured the acceleration in the vertical z direction, numbered AZ1ฐAZ5. Two sensors AXO and AZO was also arranged on the vibrating table. The slope model is shown in Fig. 4 below, and the sensor location diagram is shown in Fig. 5 below.

\subsection{Model test seismic wave loading scheme}

The test used Wenchuan wave (WC) as the loading seismic wave. The acceleration time history curve is shown in Fig. 6. The loading seismic wave was divided into Wenchuan horizontal seismic wave (WC-x), Wenchuan vertical seismic wave (WC-z), Wenchuan horizontal and vertical composite Wave (WC-xz) three kinds of seismic waves. The acceleration peaks of these three seismic waves had four peaks of $0.1 \mathrm{~g}$, $0.2 \mathrm{~g}, 0.4 \mathrm{~g}$, and $0.6 \mathrm{~g}$. When loading seismic waves, the seismic waves with smaller peaks are first loaded, and then the peaks of seismic waves waas gradually increased. Vibrate and then load the bidirectional seismic wave.

When the horizontal seismic wave was loaded, the peak value of the seismic wave gradually increases from $0.1 \mathrm{~g}$ to $0.6 \mathrm{~g}$. Since the time when the vertical seismic wave reaches the peak was generally not synchronized with the horizontal seismic wave, referring to the building seismic design code (2011), this 
test used $2 / 3$ of the horizontal seismic wave peak as the vertical seismic wave loading peak. The seismic waves in the two directions was processed according to the above method and then synthesized, and input as horizontal and vertical synthesized waves, and was loaded gradually. The loading scheme is shown in Table 4 below.

\section{Model Test Results And Analysis}

\subsection{Results and analysis of slope acceleration response}

The acceleration response peak value and acceleration amplification factor are used to analyze the slope acceleration response characteristics. The acceleration amplification factor is defined as the ratio of the peak acceleration response of the slope measured under the excitation of unidirectional and bi-directional seismic waves at a certain measuring point to the peak acceleration response of the same direction measured on the vibrating table.

The measured acceleration time history curves of the measuring point AX2 under the excitation of WC-x and WC-xz with a peak value of $0.4 \mathrm{~g}$ are shown in Fig. 7 below.

\subsubsection{Analysis of horizontal acceleration response results}

Take the horizontal acceleration response of the slope under the excitation of WC-x and WC-xz as examples.

(1) Fig. 8 shows the trend of the horizontal acceleration amplification factor of each measuring point of the slope with the relative height of the slope under different working conditions. It can be seen from Fig. 8 that under WC-x unidirectional and WC-xz bidirectional excitation, the horizontal acceleration magnification coefficients of each measuring point of the slope show nonlinear changes with the slope height.

Under WC-X excitations with peak values of $0.4 \mathrm{~g}$ and $0.6 \mathrm{~g}$, the amplification Coefficient of acceleration decreases with the change of Slope Height due to the complex effect of coupling of multi-arch tunnel and strong seismic waves from the foot of slope to $2 / 5$ slope height. At this time, the slope suppresses the amplification of horizontal seismic waves. However, there is no similar trend under the excitation of WC-x waves with peaks of $0.1 \mathrm{~g}$ and $0.2 \mathrm{~g}$. With the progressive loading of seismic wave and the increase of the peak value of seismic wave, the strain of slope increases, the shear modulus decreases, the natural vibration frequency decreases and the damping ratio increases. At the same time, the material also exhibits nonlinear characteristics. As the input amplitude increases, the filtering effect of the material increases. These factors weaken the dynamic response of the material. Therefore, there is a phenomenon that the rock mass at the lower part of the slope suppresses seismic waves, and the acceleration amplification factor at this time is smaller than the amplification factor under the seismic wave excitation with a small peak value. Above the rock layer interface at $3 / 5$ slope height, the acceleration magnification coefficient increases obviously, and it increases sharply near the slope top. It shows that the type of slope 
rock mass affects the amplification of acceleration. In addition, there is an empty surface near the top of the slope, where the complex wave field is superimposed and enhanced, and the acceleration amplification effect is more obvious.

Under the excitation of WC-xz, the acceleration amplification factor increases rapidly from the slope toe to the $3 / 5$ height of the rock layer interface. From the height of $3 / 5$ to the height of $4 / 5$, the acceleration amplification coefficient increases slowly. It increases sharply near the top of the slope. When the seismic wave propagates to the slope surface through the slope, the seismic wave will split into many different types of waves due to the interaction between the seismic wave and the rock mass. There is an empty surface on the upper side of the slope. Different types of seismic waves influence and overlap each other in a limited space. This complicates the wave field. And when the seismic wave propagates near the top of the slope, the constraints are reduced, so the amplification factor has a larger increase near the top of the slope. Compared with the unidirectional excitation, under the bi-directional excitation, the weak surrounding rock has weakened the seismic wave suppression effect. As the slope height increases, the acceleration amplification factor increases sharply at the $3 / 5$ height rock layer interface. Above $3 / 5$ height, the acceleration amplification factor decreases. The weak surrounding rock slope of the slope has the effect of suppressing horizontal seismic waves. This is more obvious than in the case of unidirectional excitation. It can be inferred that the direction of excitation also has an impact on the amplification effect of acceleration. The analysis shows that in the tunnel overlying slope, the rock boundary is easily damaged in the earthquake, and special attention should be paid to the reinforcement of the rock boundary.

(2) Fig. 9 shows the measured acceleration Fourier spectrum of sensors $A X 0, A X 3$, and AX5 under WC- $X$ unidirectional excitation with an excitation peak of $0.4 \mathrm{~g}$.

It can be seen from Fig. 9 that the excellent frequencies of the acceleration of the vibrating table are distributed in the two frequency bands of $3 \sim 5 \mathrm{~Hz}$ and $7 \sim 12 \mathrm{~Hz}$, and the acceleration frequency of the measuring point AX3 near the midpoint of the slope surface is $2 \sim 5 \mathrm{~Hz}$ and $7 \sim 10 \mathrm{~Hz}$. The acceleration frequency of the measuring point $A X 5$ at the top of the slope is distributed in two frequency bands of $3 \sim$ $5 \mathrm{~Hz}$ and $7 \sim 9 \mathrm{~Hz}$. The remarkable frequency amplitudes at the measuring points AX3 and AX5 are obviously smaller than those at the mesa measuring point. It can be seen that after the coupling of the double-arch tunnel and the slope, the seismic wave has a more significant spectral change. Because of the weak characteristics of the slope rock mass, its own damping can consume the energy of the seismic wave to a certain extent, and the existence of the double-arch tunnel itself and its inner void surface also diverges and consumes part of the energy of the seismic wave to a certain extent. Therefore, the slope has a filtering effect on the higher frequency band of seismic waves.

\subsubsection{Analysis of vertical acceleration response results}

The vertical acceleration response of slope under WC-z and WC-xz excitation is analyzed as examples. 
(1) Fig. 10 shows the trend of the vertical acceleration magnification factor of each measuring point of the slope with the relative height of the slope. Because the acceleration amplification effect is affected by the relative elevation, slope body, double-arch tunnel, rock mass properties and other factors, under the excitation of WC-z unidirectional and WC-xz bidirectional seismic waves, the vertical the acceleration amplification factor also shows a non-linear change trend in general. Under the unidirectional excitation of WC-z, due to the coupling of seismic waves and the multi-arch tunnel and the influence of the gravity of the slope, the acceleration amplification factor increases slowly from the foot of the slope to the interface of the $3 / 5$ slope height. Near the bottom of the slope, under the excitation of the seismic wave with a larger peak, the acceleration amplification coefficient is smaller than that under the seismic excitation with a smaller peak, which is similar to the situation under the $x$-directional seismic wave excitation. After the seismic wave with the smaller peak value is excited, then the large peak seismic wave is performed. The shear strength and shear modulus of the rock mass are reduced. In addition, the frequency of the rock mass is reduced and the damping ratio is increased, showing more nonlinearity, and enhancing the suppression of seismic waves. Therefore, the acceleration amplification factor under the excitation of large peak seismic waves in the lower part of the rock mass is smaller than that under the excitation of peak seismic waves. When the slope height is above $3 / 5$ and close to the top of the slope, the acceleration amplification coefficient increases rapidly, and the value increases rapidly. It can be seen that acceleration amplification is also related to the type of slope rock mass. Under unidirectional Wenchuan wave excitation, the worse the rock mass type of the weak surrounding rock slope, the more significant the vertical acceleration amplification effect. Because the upper rock mass is less restricted and its own weight is smaller than that of the lower one, the acceleration amplification factor is larger, and the slope has more violent movement.

When WC-xz is excited, as the excitation peak value increases, the amplification factor decreases. Moreover, the magnification factor first increased and then decreased with the increase of slope height. The acceleration magnification factor reaches the maximum at the interface of the rock strata. Above this height, the vertical acceleration magnification factor decreases, which is opposite to the result under unidirectional excitation. It can be inferred that the direction of seismic wave excitation also affects the acceleration dynamic response of weak surrounding rock slopes. It can be seen from Fig. 10 that under low-peak seismic wave bidirectional excitation, the slope has a strong amplification effect on seismic wave acceleration, but under high-peak seismic wave excitation, the amplification effect is lower. This is related to the early vibration. Under the excitation of low-peak seismic waves, the soils squeeze and deform each other, resulting in elastic, elasto-plastic deformation and contact deformation. Therefore, the effective contact stress increases, the frequency of the model itself decreases, and the damping ratio increases. When multiple excitations occur, the shear strength and shear modulus of the soil decrease, its own frequency decreases, and the damping ratio increases. When the excitation peak value increases, the soil appears plastic deformation and the soil softens. As the shear strength and shear modulus decrease, the effective contact stress increases at a slower rate, and the frequency and damping ratio tend to stabilize. The slope's suppression of seismic waves becomes stronger, and the above phenomenon appears. This phenomenon is more obvious under bidirectional seismic wave excitation than under 
unidirectional excitation. In the process of seismic wave propagation, when encountering the interface of different media, the wave field splitting will occur. The split seismic wave will be refracted and reflected on the slope surface.

(2) Fig. 11 shows the acceleration Fourier spectrum of acceleration sensors AZO and AZ5 under WC-Z excitation with a peak value of $0.4 \mathrm{~g}$. After the vertical seismic wave loaded by the vibrating table surface interacts with the slope, the frequency spectrum component changes significantly. In addition, the remarkable frequency and its amplitude have also changed greatly. The excellent frequency measured by the table is $1 \sim 3 \mathrm{~Hz}$ and $7 \sim 13 \mathrm{~Hz}$, and the excellent frequency measured by AX5 is $6 \sim 10 \mathrm{~Hz}$. It can be inferred that the slope also has a filtering effect on vertical seismic waves.

(3) Comparing Fig. 8(a) and Fig. 10(a), it is found that the slope has different amplification characteristics for horizontal seismic waves and vertical seismic waves. Under the unidirectional excitation of WC-x, the acceleration amplification factor tends to increase greatly from the foot of the slope to the height of $3 / 5$, and it also increases sharply near the top of the slope. Under the unidirectional excitation of WC-z, the vertical acceleration magnification coefficient increases from the foot of the slope to $3 / 5$ of the slope height. It increases rapidly from the height of $3 / 5$ (the boundary of the strata) to the top of the slope. At the foot of the slope, the maximum value of the vertical acceleration amplification factor is 1.597, and the peak value of the horizontal acceleration amplification factor at the same location is 1.987. Near the middle of the slope, the peak value of the amplification factor of vertical acceleration under WC-z excitation is 1.81 , and the peak value of the amplification factor of horizontal acceleration under WC-x excitation is 2.12. Near the top of the slope, the peak value of the amplification factor of the vertical acceleration under WC-z excitation is 2.569 , and the peak value of the amplification factor of the horizontal acceleration under WC-x excitation is 2.872 . When it is near the top of the slope, the vertical acceleration magnification coefficients are not much different under the excitation of the larger peak seismic wave, which are all around 2.6. The horizontal acceleration magnification factor is distributed more scattered, and the difference is large. It can be seen that near the top of the slope, the weak surrounding rock slope is more affected by vertical seismic waves.

(4) It can be seen from Fig. 8 and Fig. 10 that under the excitation of WC-xz, when the peak value of the seismic wave increases, the magnification factor generally shows the characteristic of decreasing. Under unidirectional seismic wave excitation, as the peak value of seismic wave excitation increases, the slope horizontal and vertical acceleration amplification coefficients generally show an increasing trend, which is related to the nonlinearity of the slope rock mass and seismic wave excitation. In addition, the coupling between the Wenchuan wave and the double-arch tunnel and the existence of the interface will also affect the occurrence of this trend. As the peak value of the seismic wave increases, the slope strain will increase. At the same time, the slope shear modulus decreases, and the slope natural frequency will also be affected and reduced. In addition, due to the increase of the damping of the slope material, the nonlinear characteristics of the rock mass appear, and there are structural planes and structural planes in the slope. Therefore, the seismic waves in the propagation path are reflected and refracted. The 
superposition of various seismic waves results in a more complicated seismic wave field on the slope and result in the acceleration response characteristics described above.

\subsection{Dynamic displacement response law \\ 3.2.1 Analysis of Response Characteristics of Slope Horizontal Dynamic Displacement}

The horizontal dynamic displacement response characteristics of the slope under the excitation of WC-x and WC-xz are studied.

Figure 12 is the time history curve of the horizontal dynamic displacement response of the measuring point DX3 under the excitation of WC-X and WC-XZ with a peak value of $0.4 \mathrm{~g}$. Figure 13 shows the relationship between the peak value of the horizontal dynamic displacement response of the measuring point DX5 and the peak value of acceleration excitation. Figure 14 shows the distribution of the horizontal dynamic displacement response peaks along the slope height at each measurement point of the slope under different seismic wave peak conditions.

Analyzing Fig. 13, under the excitation of WC-z seismic wave, the magnitude of the excitation peak does not significantly change the peak of the horizontal dynamic displacement response, but the peak of the horizontal dynamic displacement response gradually increases under the $x$ unidirectional and $x z$ bidirectional excitations. It can be seen that the slope horizontal dynamic displacement response peak is mainly affected by the horizontal seismic wave, and the horizontal dynamic displacement response peak increases with the increase of the acceleration peak.

(1)Fig. 14 shows that under the excitation of WC-x and WC-xz seismic waves, the peak value of horizontal dynamic displacement generally gradually increases with the increase of slope height under various working conditions, and the response peak value is below the boundary of the strata. The growth rate is relatively slow. Above the rock boundary, the rate of increase increases. And near the top of the slope, the increasing trend is rapid, basically reaching the maximum. It can be seen from the figure that a large horizontal displacement occurs near the top of the slope, and the slope is easily damaged. From a longitudinal comparison, for the same seismic wave, the slope dynamic displacement response peak under high-peak seismic wave excitation is generally larger than that under low-peak seismic wave excitation. In the surrounding rock at the lower part of the slope, due to the weight of the surrounding rock and the better grade of the surrounding rock, its stiffness is greater than that of the upper surrounding rock, and it is more restrained, making the peak horizontal dynamic displacement of the slope smaller. At the interface between the two layers of surrounding rocks, the dynamic displacement response peak is still small due to the mutual friction between the surrounding rocks and the weight of the surrounding rocks. In the upper surrounding rock, due to its poor grade and less restraint, the dynamic displacement response is severe. 
(2)The horizontal dynamic displacement of the slope under WC-xz excitation is greater than that under WC-x excitation. And the peak value of dynamic displacement under WC-z excitation is the smallest. However, under WC-z excitation, the peak value of the horizontal dynamic displacement response generally increases with the increase of the slope height. It can be inferred that the dynamic displacement response of the slope is mainly affected by the seismic wave in the same direction, and the vertical seismic wave will also affect the horizontal. In summary, the peak dynamic displacement response of the slope is affected by factors such as the direction of the seismic wave, the intensity of the excitation, the characteristics of the surrounding rock itself, and the location of the displacement measurement point.

\subsubsection{Analysis of response characteristics of slope vertical dynamic displacement}

The vertical dynamic displacement response characteristics of the slope under WC-z and WC-xz excitation are studied.

Analyzing Fig. 16, with the increase of the excitation peak value, the vertical dynamic displacement peak value does not change significantly under WC-x excitation. Under WC-z and WC-xz excitations, the slope dynamic displacement response peak value changes nonlinearly and gradually increases with the increase of the acceleration peak value. It can be seen from the graph analysis that the vertical dynamic displacement is mainly related to the vertical seismic wave excitation. The peak value of the vertical dynamic displacement of the measuring point DZ5 increases with the increase of the peak value of the excitation.

(1)Analyzing Fig. 17, from a longitudinal comparison, under the same seismic wave excitation, as the peak value increases, the vertical dynamic displacement response peak value of the same measuring point gradually increases. After repeated excitations, the surrounding rock gradually softened and showed more nonlinearity. The peak value of the vertical dynamic displacement response of each measuring point of the slope generally decreases first and then increases. Due to the good grade of the surrounding rock, the higher stiffness, strength and dead weight, etc, the lower surrounding rock of the slope has stronger seismic wave suppression than the upper surrounding rock. The vertical dynamic displacement response peak value is generally decreasing below the boundary of the rock. At the $3 / 5$ slope height, the boundary between the rock layers, the vertical dynamic displacement response peak is the smallest because of the friction between the two surrounding rocks and the weight of the surrounding rock. Above this point, the slope is restricted and reduced, and the peak vertical dynamic displacement increases rapidly. The peak value of vertical dynamic displacement under bidirectional seismic wave excitation is greater than that under unidirectional excitation.

(2)From a horizontal comparison, the peak value of dynamic displacement response under WC-z excitation is larger than that under WC-x excitation. Under the excitation of WC-x, the peak value of the vertical dynamic displacement response tends to increase as a whole. It can be seen that the vertical dynamic displacement will also be affected by horizontal seismic waves, especially when the type of surrounding rock is poor. Under the WC-xz bidirectional excitation, the peak value of the vertical dynamic 
displacement response is greater than that of the unidirectional excitation. It shows that the dynamic response of the slope caused by bi-directional seismic waves is greater than that of unidirectional seismic waves, and its destructiveness is also greater. According to Fig. 17, it can be inferred that in actual slope seismic engineering practice, proper attention should be paid to the vertical displacement near the toe and top of the slope, where a large vertical displacement may occur. At the same time, the dynamic displacement response of the slope is also related to the excitation direction, the characteristics of the surrounding rock itself and the location of the measuring point.

\section{Conclusion}

In this paper, a similarity ratio of 1:20 is established to model the weak surrounding rock slope of a double-arch tunnel. A shaking table test was carried out, and Wenchuan waves with different peaks were selected to excite three loading directions. The slope acceleration and dynamic displacement response characteristics were explored. The relevant conclusions are shown below.

(1)The acceleration amplification factor gradually increases with the slope height, and its change trend is nonlinear. The nature of the slope, the coupling between the double-arch tunnel and the seismic wave, and the interface between the strata will all affect this trend. The acceleration amplification effect of slope under unidirectional excitation is more obvious than under bi-directional excitation. Due to the coupling effect of the slope and the double-arch tunnel, the Fourier spectrum of the seismic wave changes greatly, and the high-frequency region of the seismic wave is more easily filtered by the slope.

(2)When the Wenchuan wave is excited in one direction, the acceleration amplification factor increases with the increase of the excitation peak. In the bilateral excitation, with the increase of the peak value of the seismic wave, the acceleration amplification factor shows a decreasing trend as a whole, and the acceleration amplification factor first increases and then decreases with the increase of the relative height of the slope. The characteristics of this change are related to the influence of the direction of seismic wave excitation, the coupling between the double-arch tunnel and the slope, and the nature of the slope rock mass.

(3)The horizontal and vertical dynamic displacement response of the weak surrounding rock slope of the double-arch tunnel is closely related to the seismic wave in the same direction. And the overall value increases with the increase of the excitation peak. It should be noted that there may be a large vertical displacement near the toe and top of the slope, and this should be paid attention to in actual engineering. The dynamic displacement response of the slope is related to the direction of seismic wave excitation and the position of the displacement measuring point.

(4)The peak value of the dynamic displacement response of the slope of the double-arch tunnel changes nonlinearly under the action of earthquake. The peak value of horizontal dynamic displacement increases slowly below the boundary of the strata, and the vertical dynamic displacement generally shows a decreasing trend. Above the height of the rock layer interface, the dynamic displacement response peak increases rapidly, and the maximum displacement occurs near the top of the slope. It is speculated that 
slope damage such as landslides and rock mass ejection are more likely to occur near the top of the slope.

It is worth noting that due to the influence of the size effect, the data obtained from the shaking table test, such as the acceleration amplification factor, are often larger than the actual situation. This situation should be paid attention to in the actual engineering design and construction process.

\section{Declarations}

\section{Author contribution}

Xueliang Jiang contributed to the conception of the study;

Yonghui Qian, Jiqi Zhang performed the experiment;

Yong Liu,Riwen Deng and LiHuang contributed significantly to analysis and manuscript preparation;

Guojie Lai helped perform the analysis with constructive discussions

\section{Data Availability Statement}

The models and related experimental parameters involved in this article are provided by the relevant authors

\section{Conflict of interest}

The authors declared that they have no conflicts of interest to this work.

We declare that we do not have any commercial or associative interest that represents a conflict of interest in connection with the work submitted

\section{Acknowledgements}

The Hunan Provincial Natural Science Foundation of China [Grant Numbers. 2020JJ4944]and Special Fund Project of Safety Production Prevention and Emergency Response in Hunan Province.

\section{References}

1. Wang JX, Tang YQ, Zhu HH. \2006₫3D Monitoring and analysis of Landslide deformationcaused by twin-arch tunnel. Chinese Journal of Rock Mechanics and Engineering, 25(11),pp.2226-2232.

2. Wang WG. ${ }_{2} 2009 \llbracket$ Research numerical simulation of the slope stability under bias of double-arch tunnel in the soft surrounding rock. $\mathrm{X} \rrbracket a n \llbracket C h a n g \square$ an University.

3. Lin H, Chen J. (2016) Back analysis method of homogeneous slope at critical state. KSCE Journal of Civil Engineering. 21(3) ,pp.670-675. https://doi.org/ 10.1007/s12205-016-0400-1. 
4. Lin H, Zhong WW, Cao P. (2015)Three-dimensional rock slope stability analysis considering the surface load distribution[J]. European Journal of Environmental and Civil Engineering. 20(8), pp.877898. https://doi.org/ 10.1080/19648189.2015.1084382.

5. Wright S G, Rathje E M. (2003)Triggering mechanisms of slope instability and their relationship to earthquakes and tsunamis[J]. Pure and Applied Geophysics, 160 (10/11),pp. 1865-

1877.https://doi.org/ 10.1007/s00024-003-2410-4.

6. Liu SL, Yang ZP, Liu XR, et al. (2018)Shaking table model test and numerical analysis of the bedding rock slopes under frequent micro-seismic actions[J].Chinese Journal Of Rock Mechanics and Engineering,37(10), pp.2264-2276.

7. Yang GL, Wen CP. (2012)Shaking table test study on dynamic response of slope with lattice framed anchor structure during earthquake[J]. Journal of Central South University (Science and Technology), 43 (4), pp. 1482-1493.

8. Lin M L, Wang K L. (2006)Seismic slope behavior in a large-scale shaking table model test[J]. Engineering Geology, 86 (2/3), pp.118-133. https://doi.org/ 10.1016/j.enggeo.2006.02.011

9. Yang GX, Wu FQ, Dong JY, et al. (2012)Study of dynamic response characters and failure mechanism of rock slope under earthquake[J]. Chinese Journal of Rock Mechanics and Engineering, 31 (4), pp.696-702.

10. Ye HL, Zheng YR, Dd XL, et al. 区2012)Shaking table model test and numerical analysis on dynamic failure characteristics of slope slope[J].China Civil Engineering Journal, 45 (9), pp.128-135.

11. Yang CW ,Gao HB, Zhang JJ. $₫ 2013 \llbracket R e s e a r c h$ on the generality and otherness of seismic responses of the steep rock slope[J]. Journal of Sichuan University( Engineering Science Edition), 45 (3), pp.1826.

12. Xu GX, YAO LK, Gao ZN,et al. $₫ 2008 \rrbracket$ Large-scale shaking table model test study on dynamic characteristics and dynamic responses of slope[J].Chinese Journal of Rock Mechanics and Engineering, 27 (3), pp. 624-632.

13. Niu JY, Jiang XL, Yang H, et al. $₫ 2018 \llbracket$ Seismic response characteristics of a rock slope with small spacing tunnel using a large-scale shaking table[J]. Geotechnical and Geological Engineering, 36(4) ,pp.2707-2723. https://doi.org/ 10.1007/s10706-018-0493-z.

14. Niu JY, Jiang XL, Wang FF, et al. $₫ 2018 \varangle$ Stability analysis of rock slope with small spacing tunnel under earthquakes and influence of ground motion parameters[J]. Geotechnical and Geological Engineering, (3),pp. 1-17. https://doi.org/ 10.1007/s10706-018-0475-1.

15. Niu JY, Jiang XL, Yang H,et al. $₫ 2017 \llbracket$ Study on dynamic response characteristics of rock slope with small spacing tunnel under earthquakes[J]. Journal of Natural Disasters, 26(5), pp.130-139.

16. Jiang XL, Niu JY Yang H, et al. $₫ 2018 \bowtie$ Large-scale shaking table test study on seismic response characteristics of hierarchic rock slope with tunnel[J]. Chinese Journal of Applied Mechanics,35(04),pp.762-768+931.

17. Jiang XL, Niu JY, Lian PY, et al. $₫ 2017 \bigotimes$ Large-scale shaking table test study on seismic response characteristics of rock slope with small spacing tunnel [J]. Engineering Mechanics, 34 (05) ,pp.132- 
18. Chen YF, Lin H. $₫ 2019 \llbracket$ Consistency analysis of Hoek-Brown and equivalent Mohr-coulomb parameters in calculating slope safety factor. Bulletin of Engineering Geology and the Environment. 78, pp.4349-61.doi:10.1007/s10064-018-1418-z.

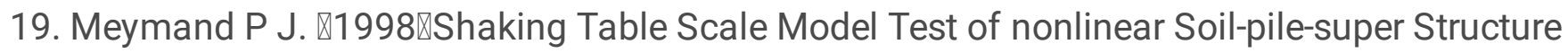
interaction in Soft Clay[D]. Berkeley: University of California.

20. Lv XL, Chen YQ, Chen B, et al. $₫ 2000 \llbracket$ Shaking table testing of dynamic soil-structure interaction system[J]. Earthquake Engineering and Engineering Vibration, 20 (4),pp.20-29.

21. GB50011-2010, $₫ 2011 \llbracket$ Code for seismic design of building [S]. Beijing: China Architecture and Building Press.

\section{Tables}

Due to technical limitations, table $1,2,3,4$ is only available as a download in the Supplemental Files section.

\section{Figures}

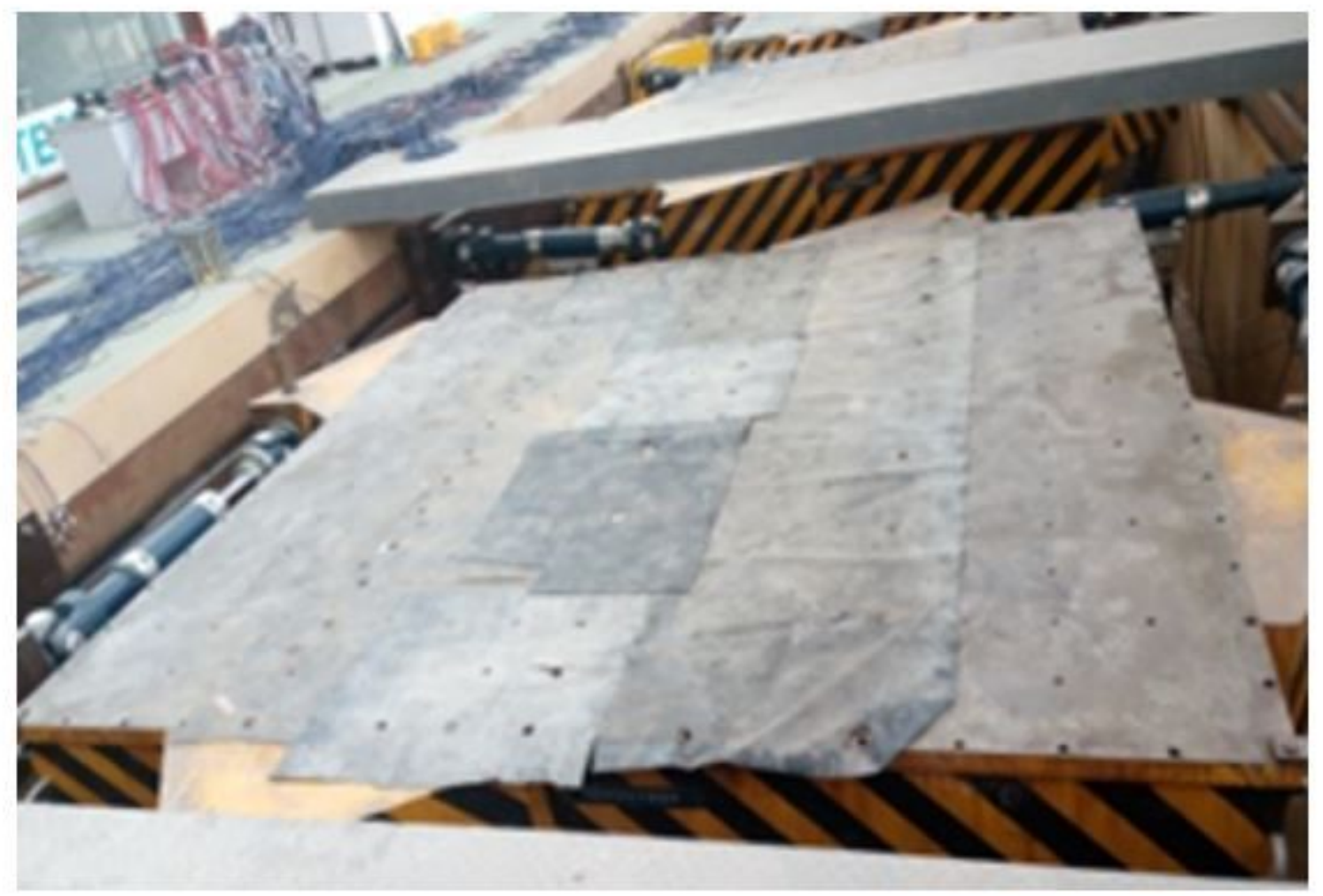

Figure 1 
Large-scale shaking table

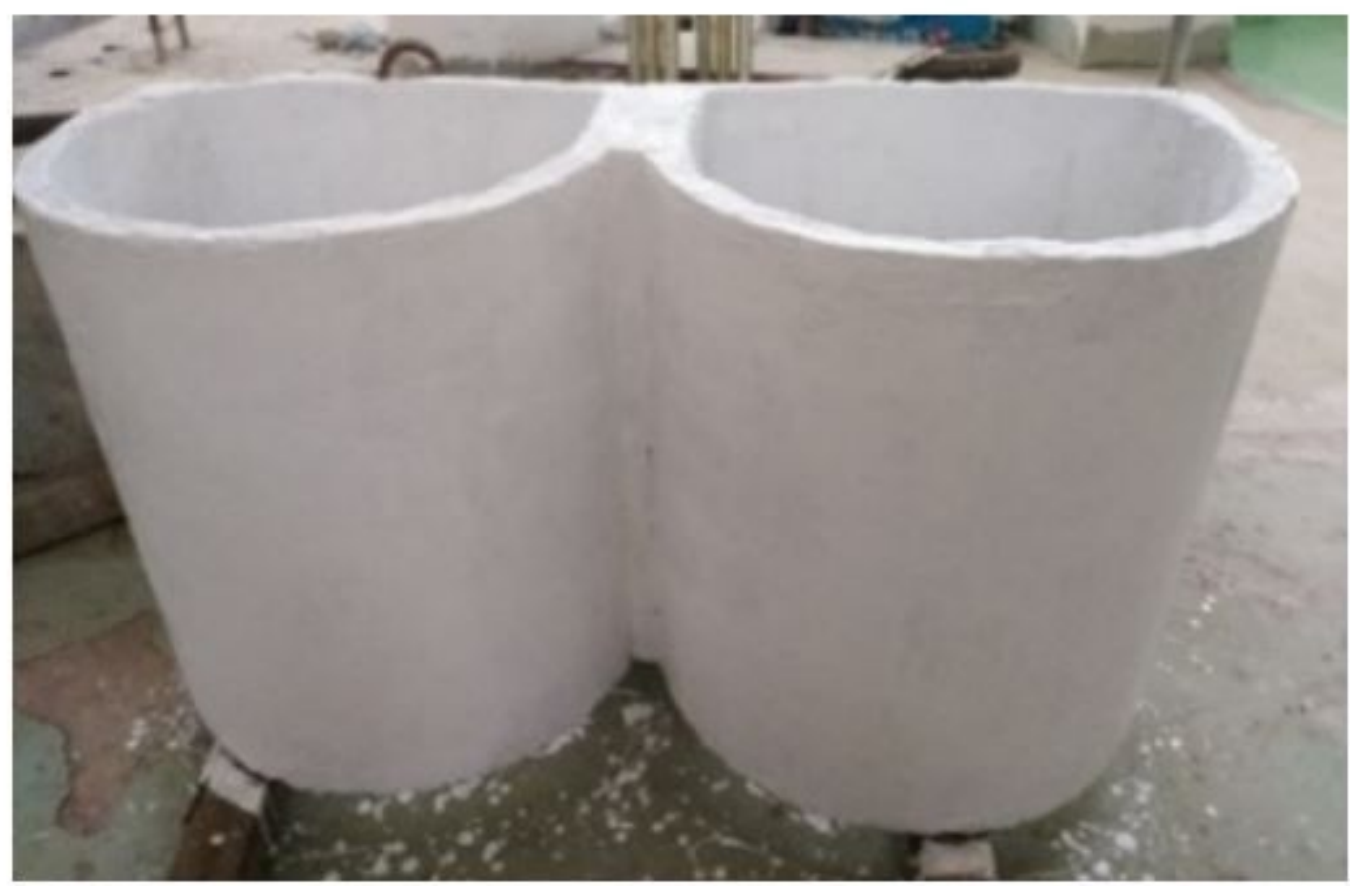

Figure 2

Lining model 


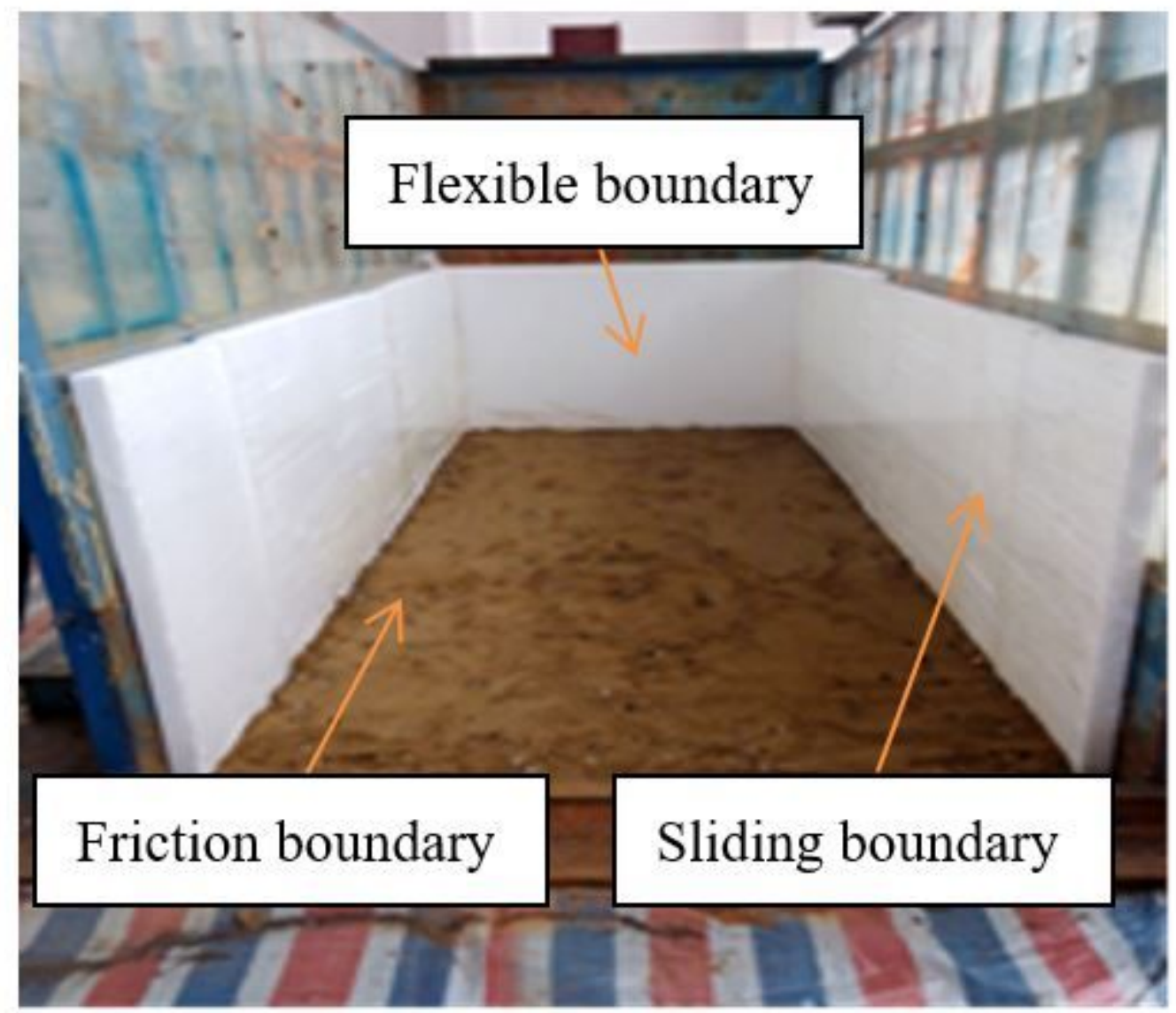

Figure 3

Processing of model box internal boundaries 


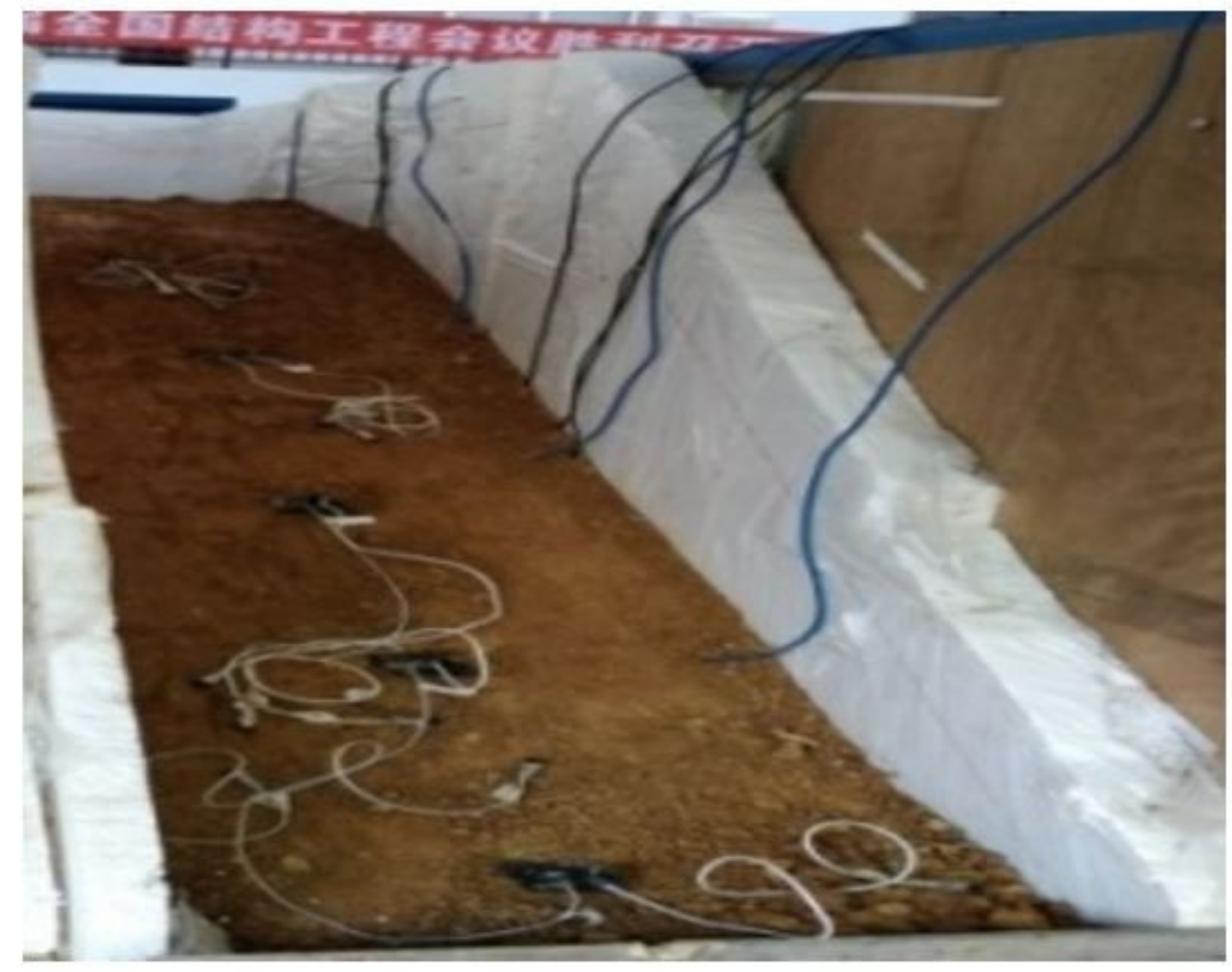

Figure 4

Profile of model slope 


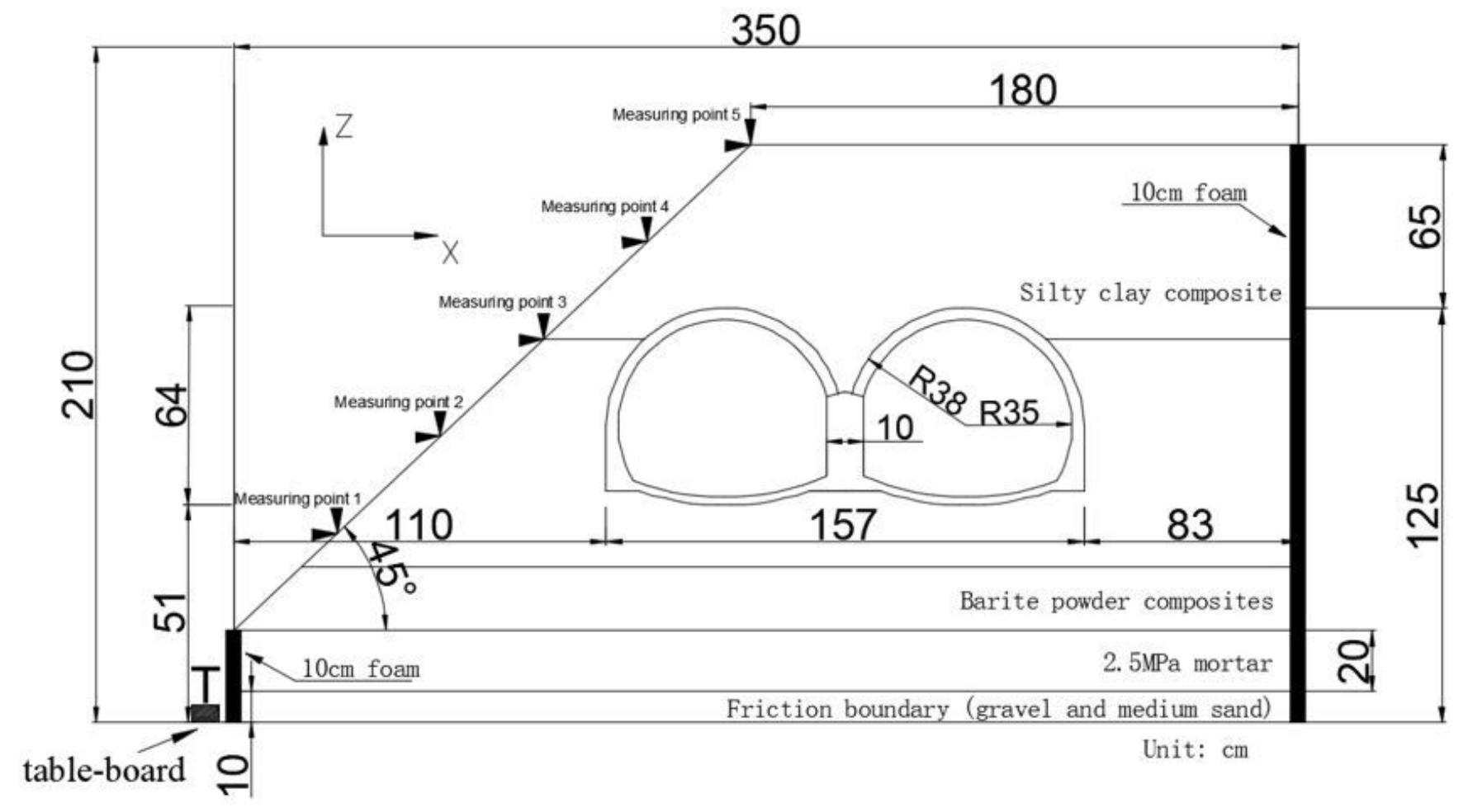

Figure 5

Locations layout of transducers

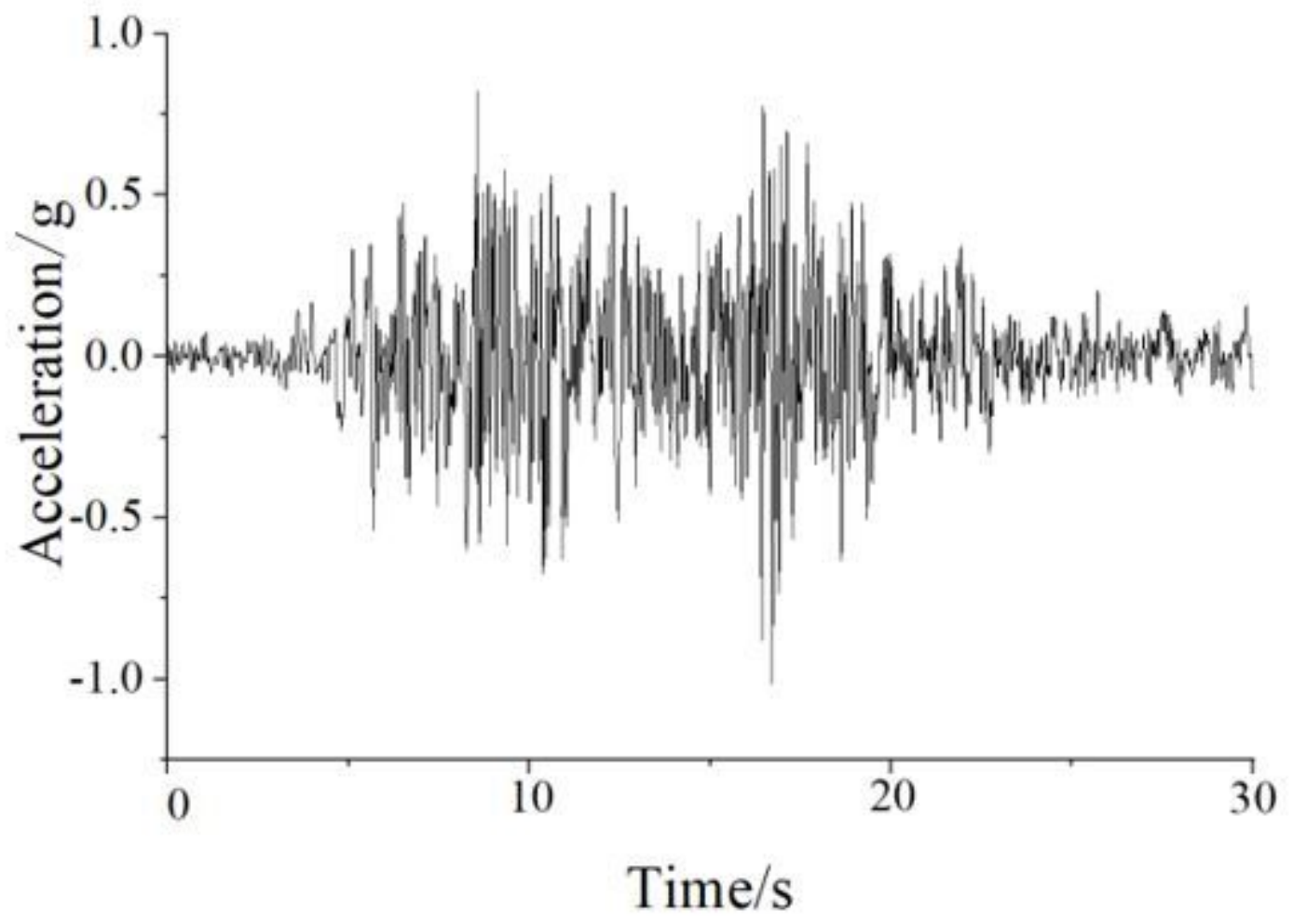

Figure 6 
Acceleration time-history of wenchuan seismic wave

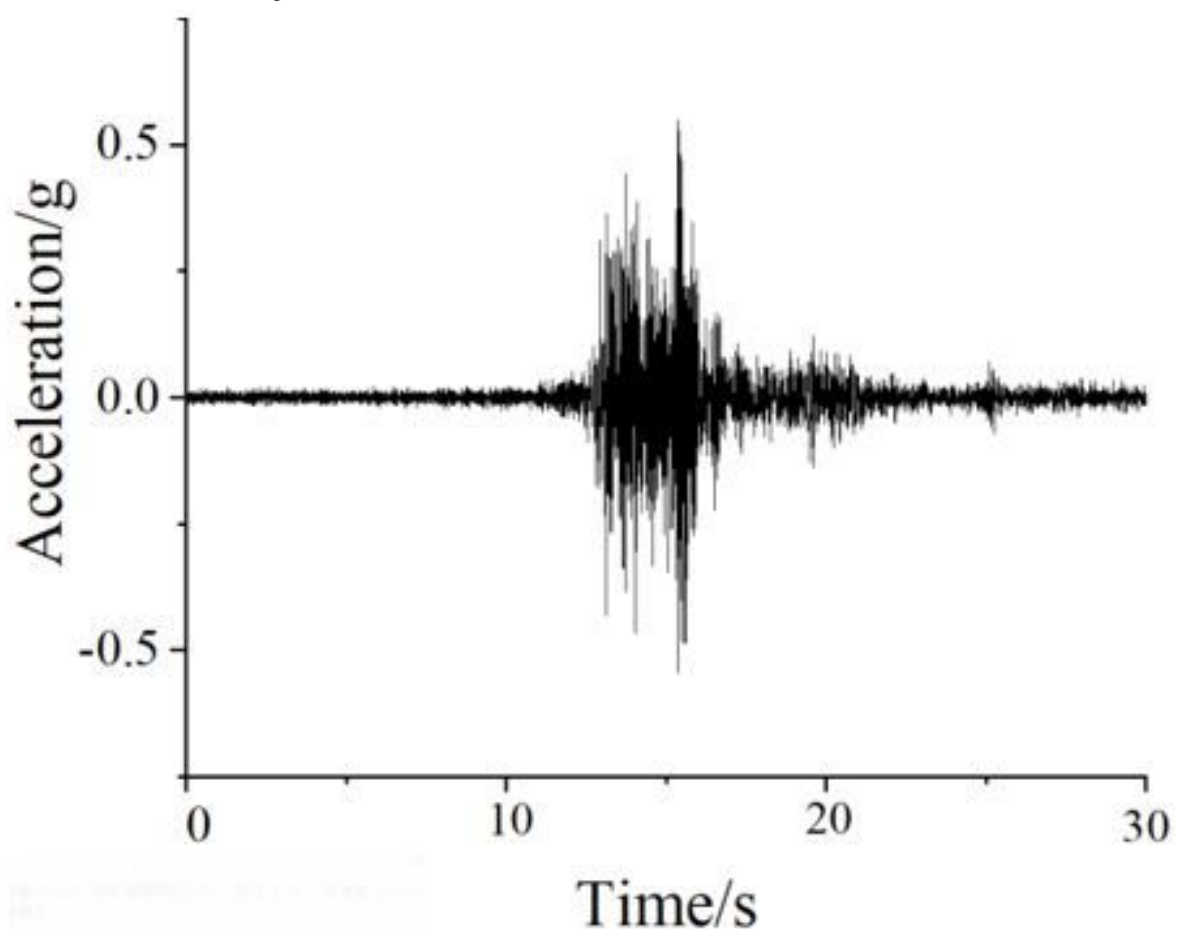

(a) WC-x

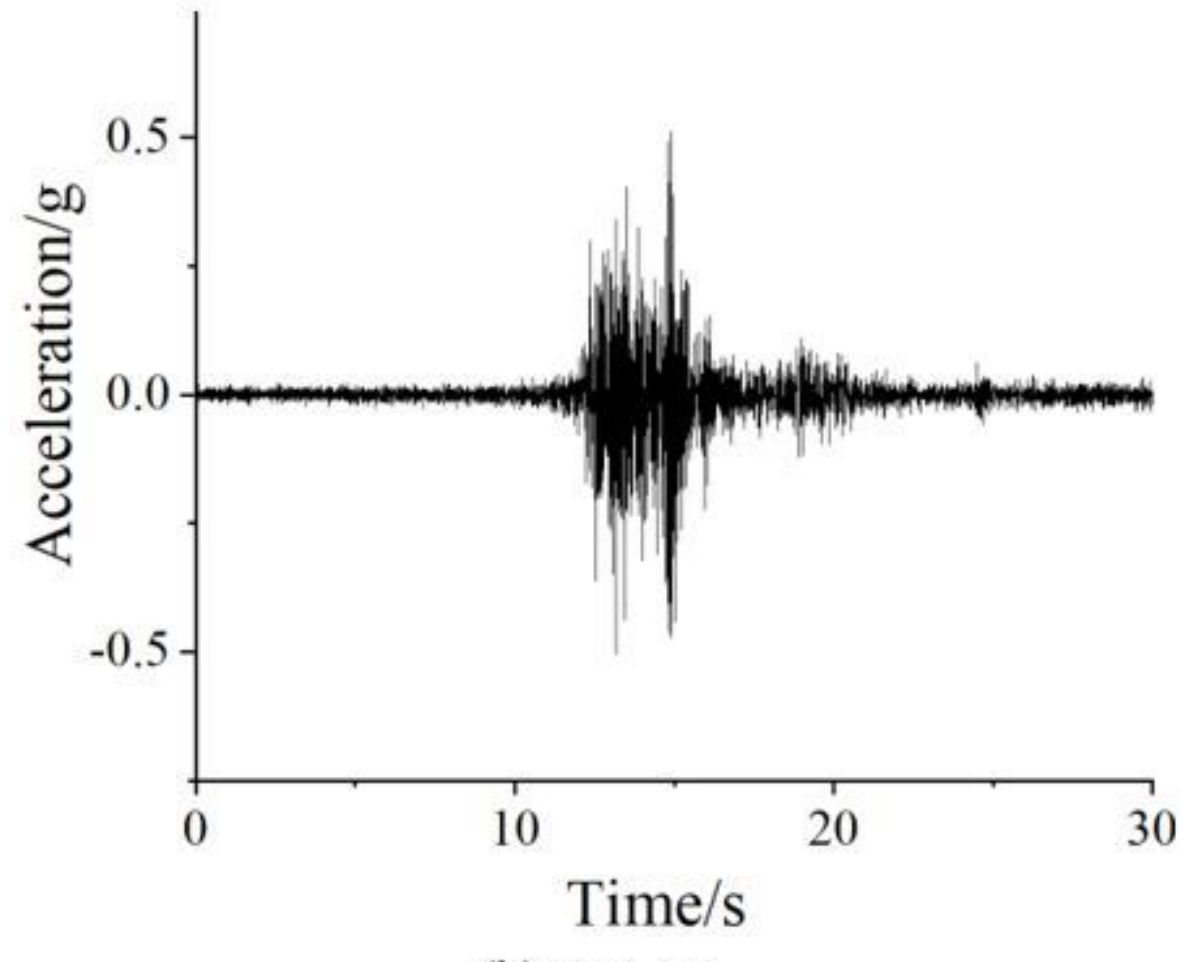

(b) WC-xz

Figure 7

Measure of the horizontal acceleration time-history response of AX2 in wc-x and wc-xz excitation 


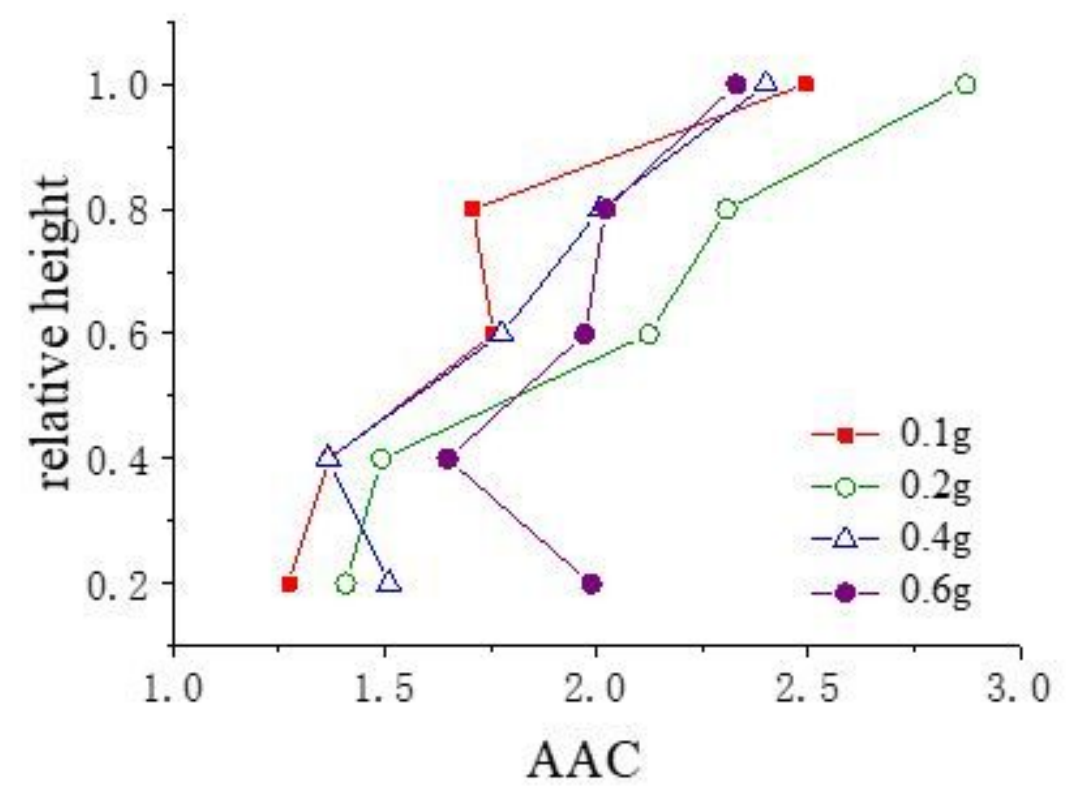

(a) WC-X

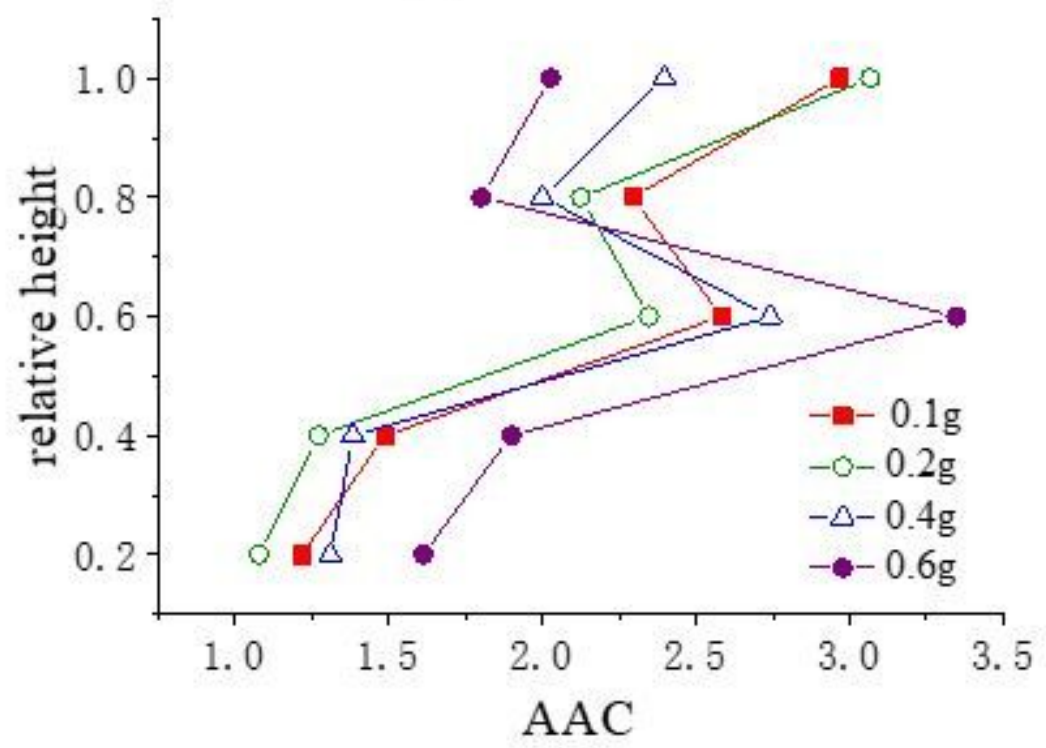

(b) WC-xz

Figure 8

Amplification coefficient change law of horizontal acceleration with height of slope 


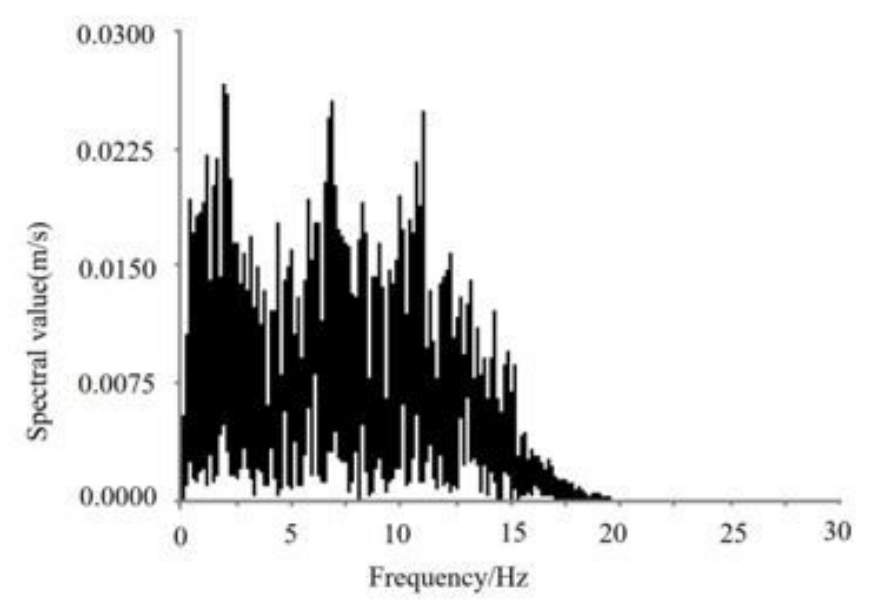

(a) AX0

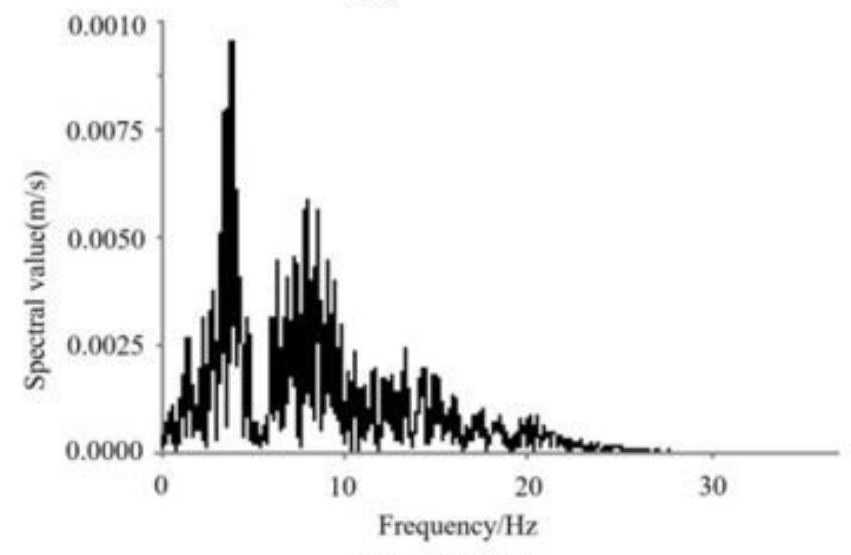

(b) $\mathrm{AX} 3$

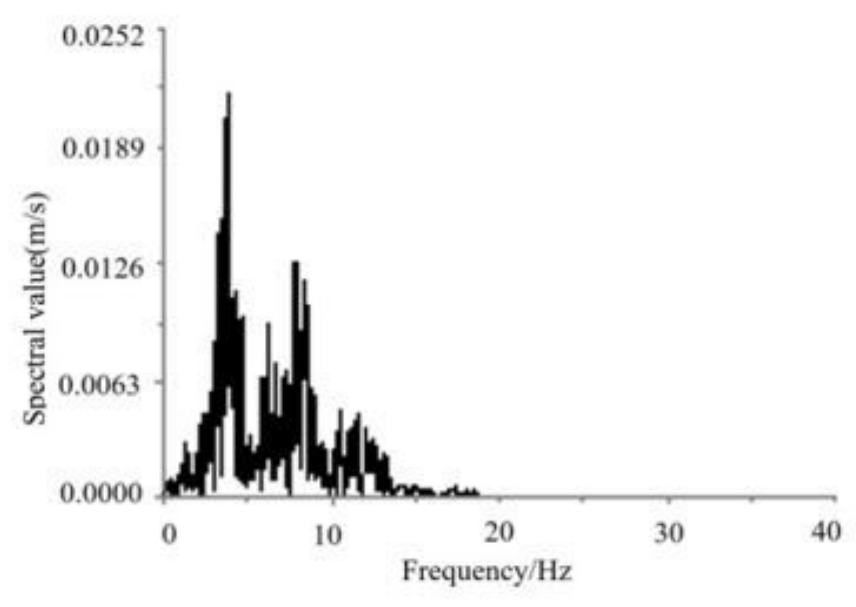

(c) AX5

Figure 9

Acceleration fourier spectrum of sensor $\mathrm{AX} 0, \mathrm{AX} 3$ and $\mathrm{AX} 5$ under the excitation of wc-X 


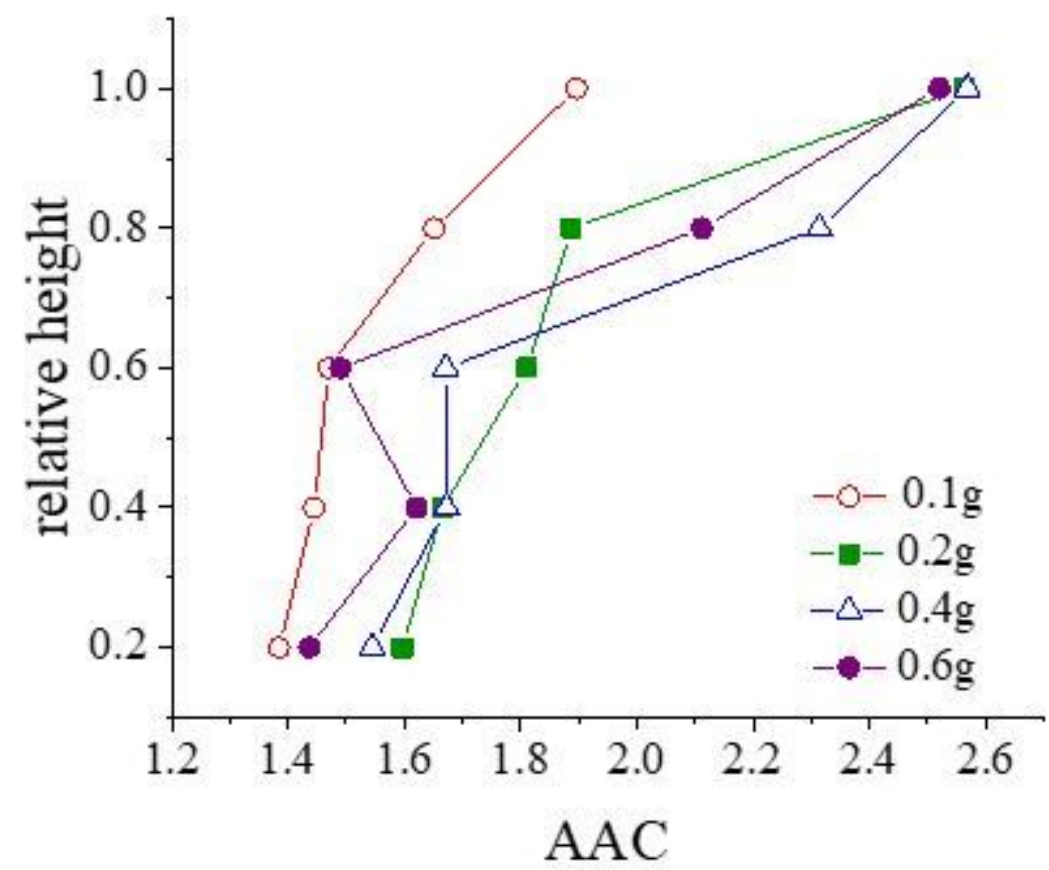

(a) WC-Z

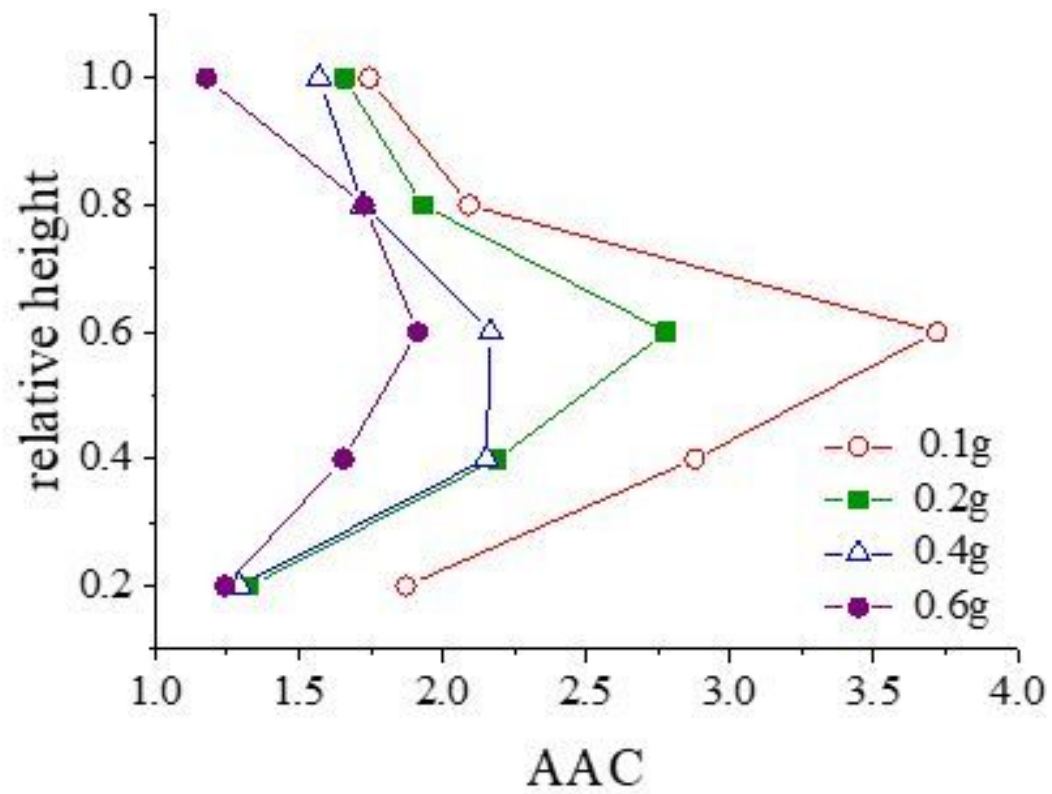

(b) WC-xz

Figure 10

Amplification coefficient change law of vertical acceleration with height of slope 


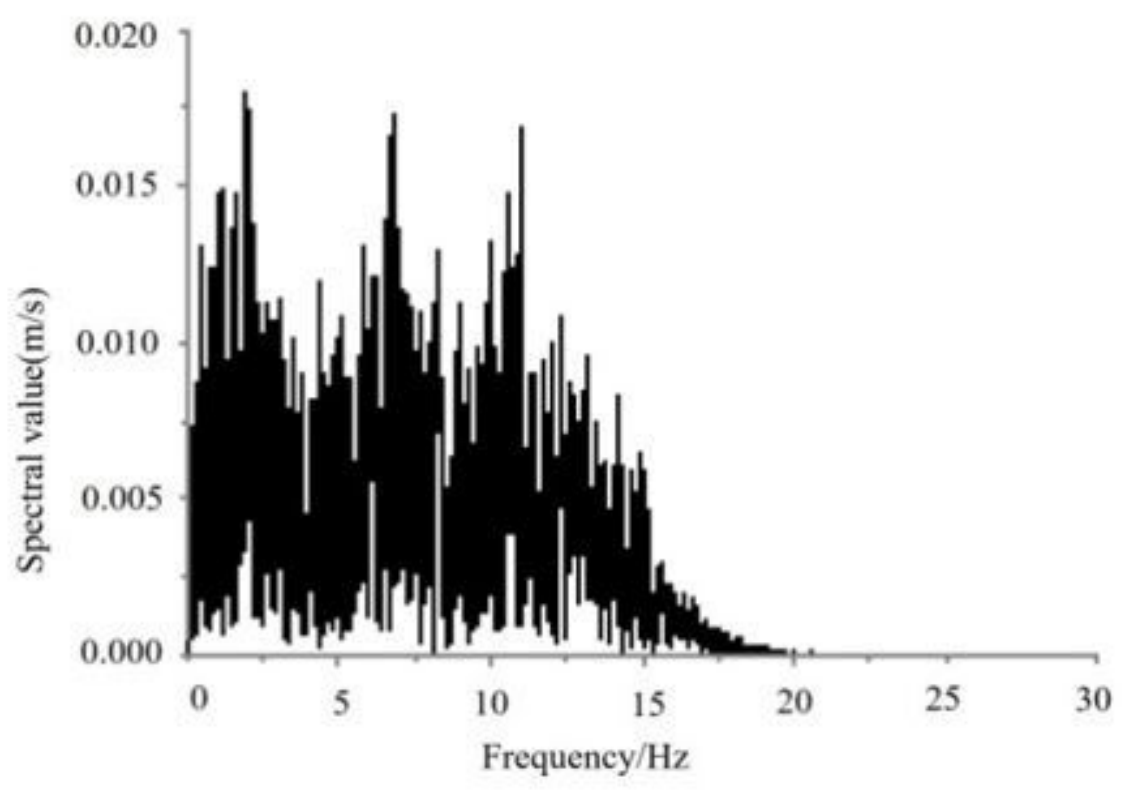

(a) $\mathrm{AZ0}$

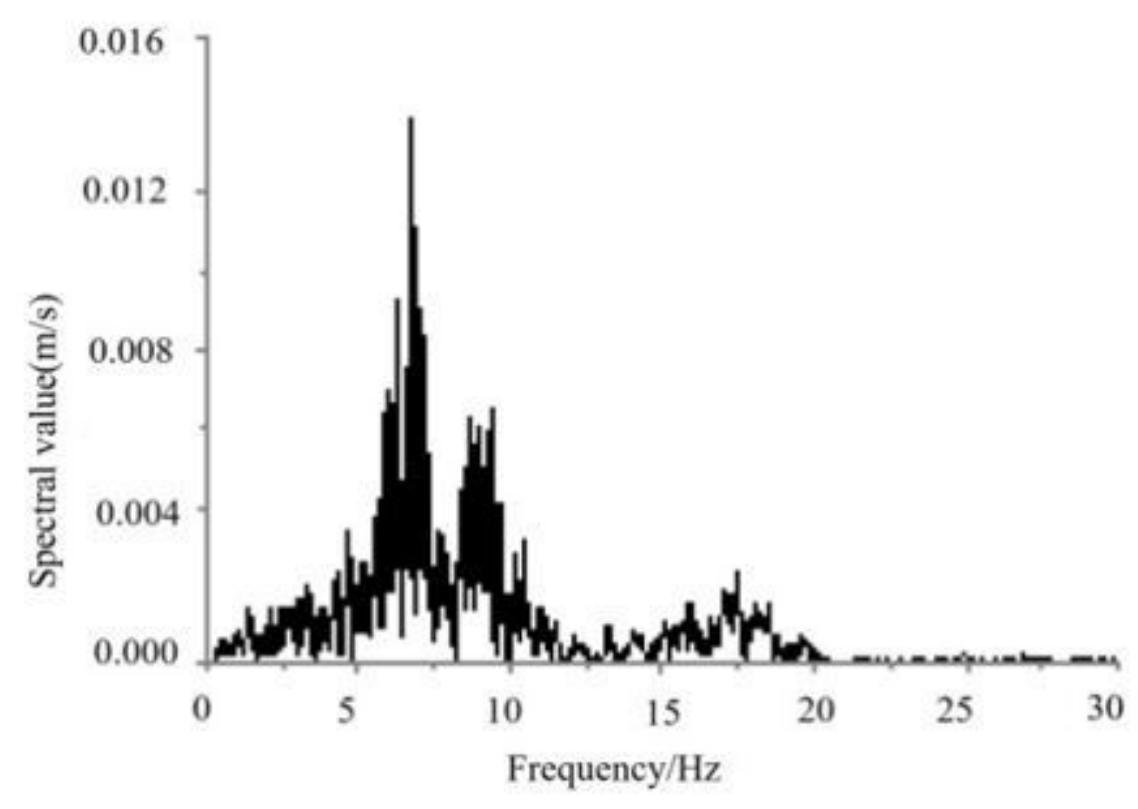

(b) $\mathrm{AZ5}$

Figure 11

Acceleration fourier spectrum of sensor AZO and AZ5 under the excitation of wc-Z 


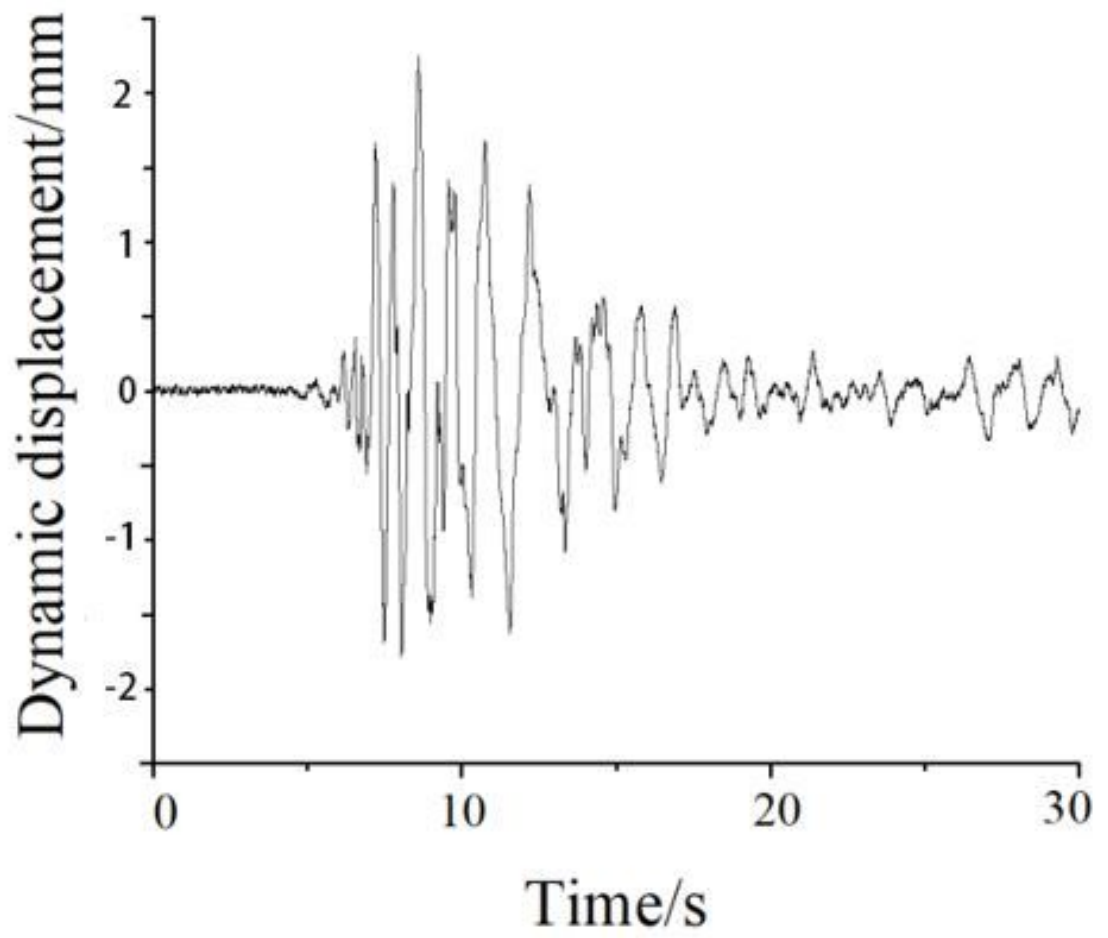

(a) WC-x

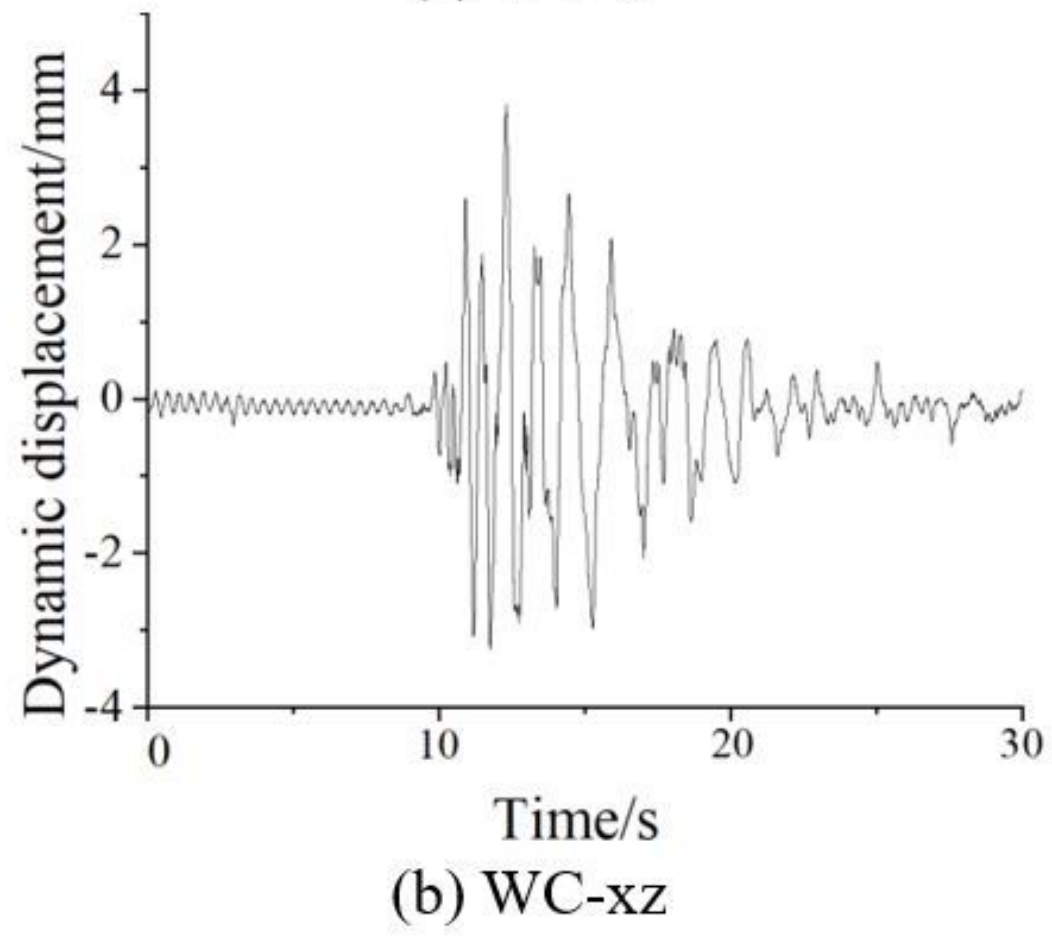

Figure 12

Horizontal dynamic displacement time-history curve measured by point DX3 


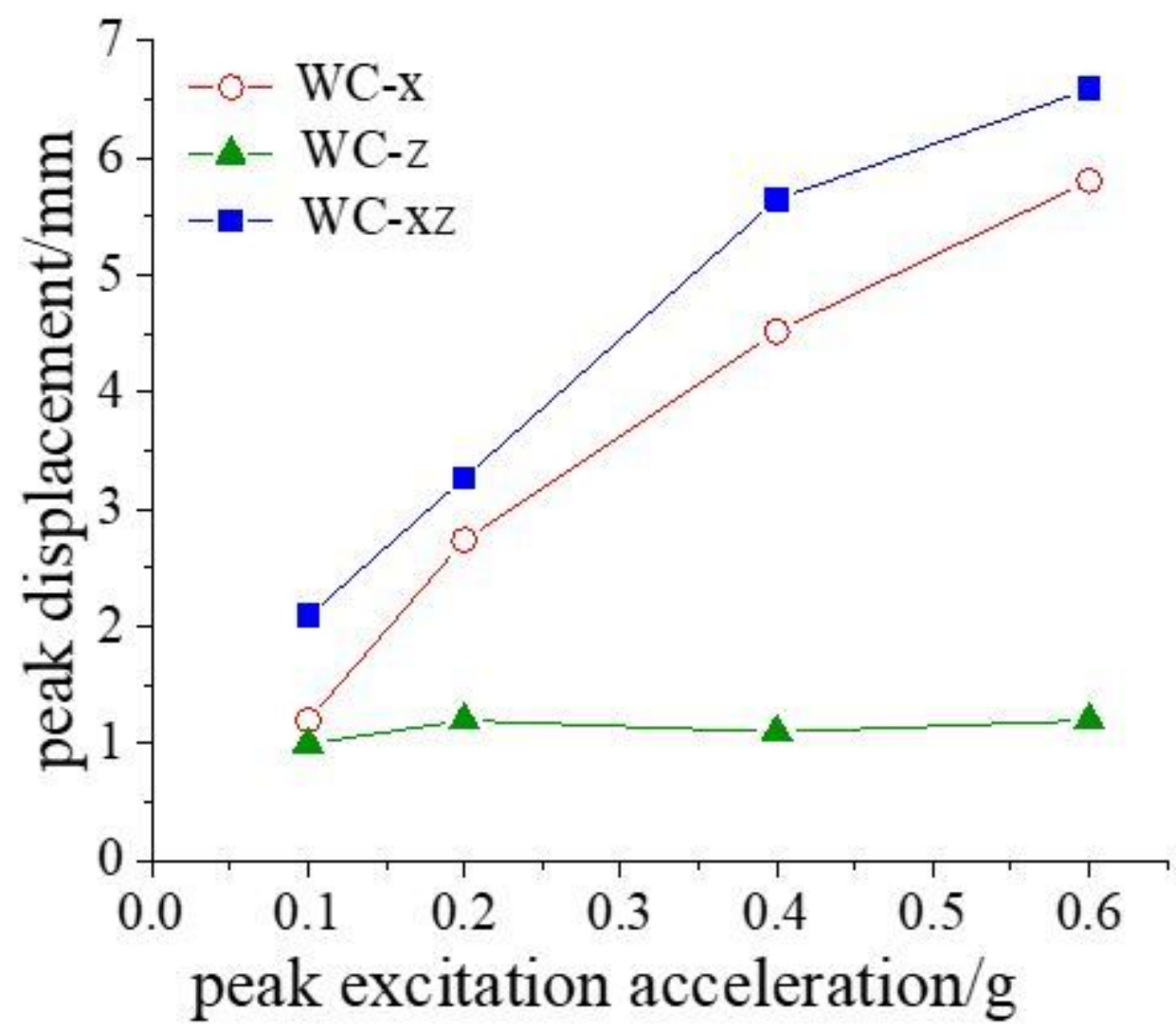

Figure 13

Relation between horizontal displacement of point DX5 with and peak load 


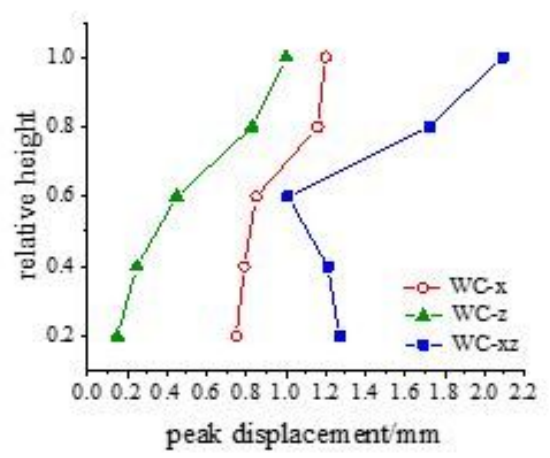

(a) $0.1 \mathrm{~g}$

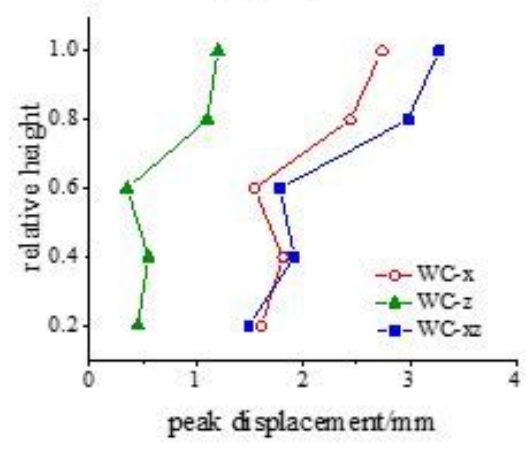

(b) $0.2 \mathrm{~g}$

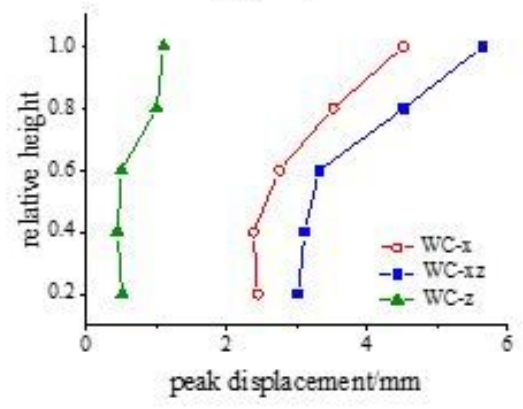

(c) $0.4 \mathrm{~g}$

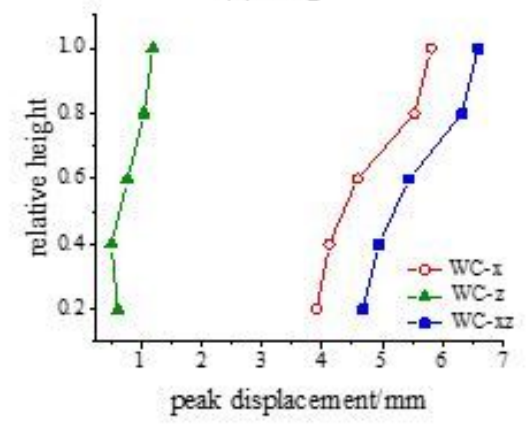

(d) $0.6 \mathrm{~g}$

\section{Figure 14}

Regular of horizontal dynamic displacement peak response varies with height of slope 


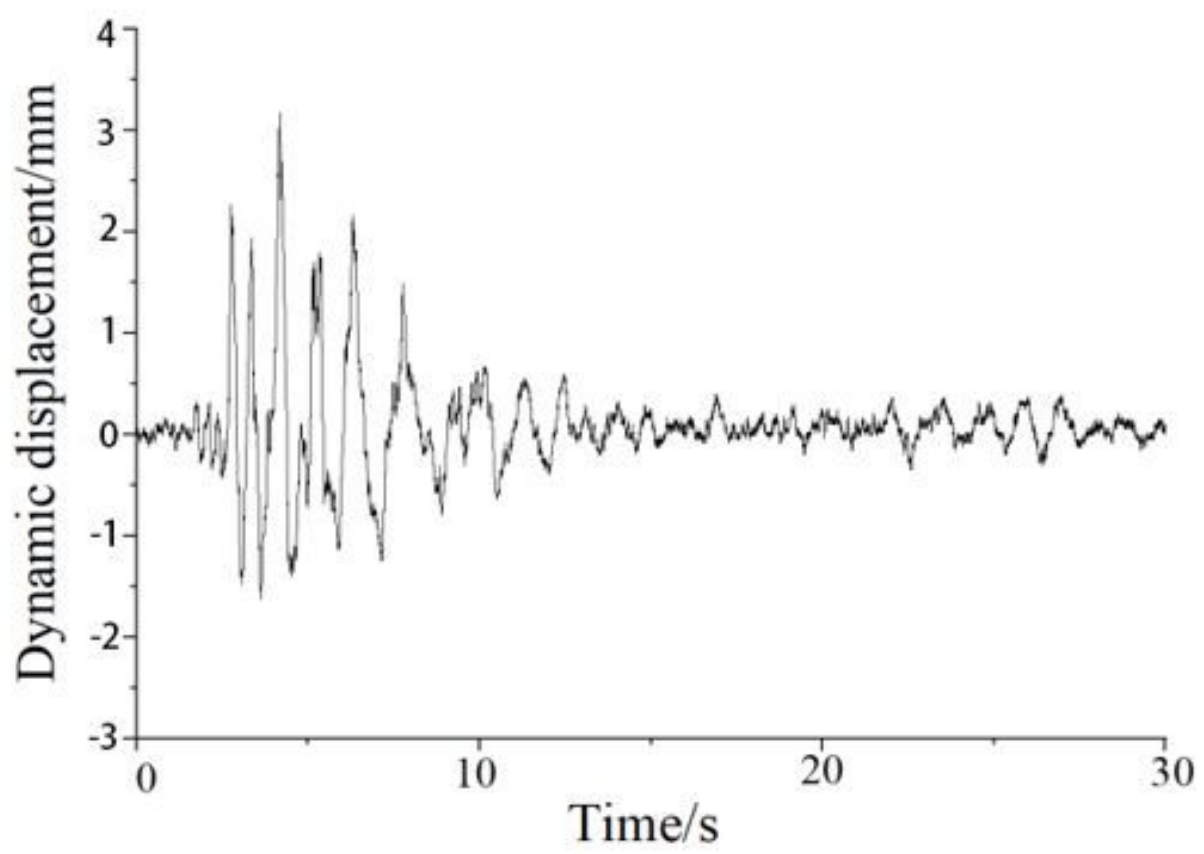

(a) WC-z

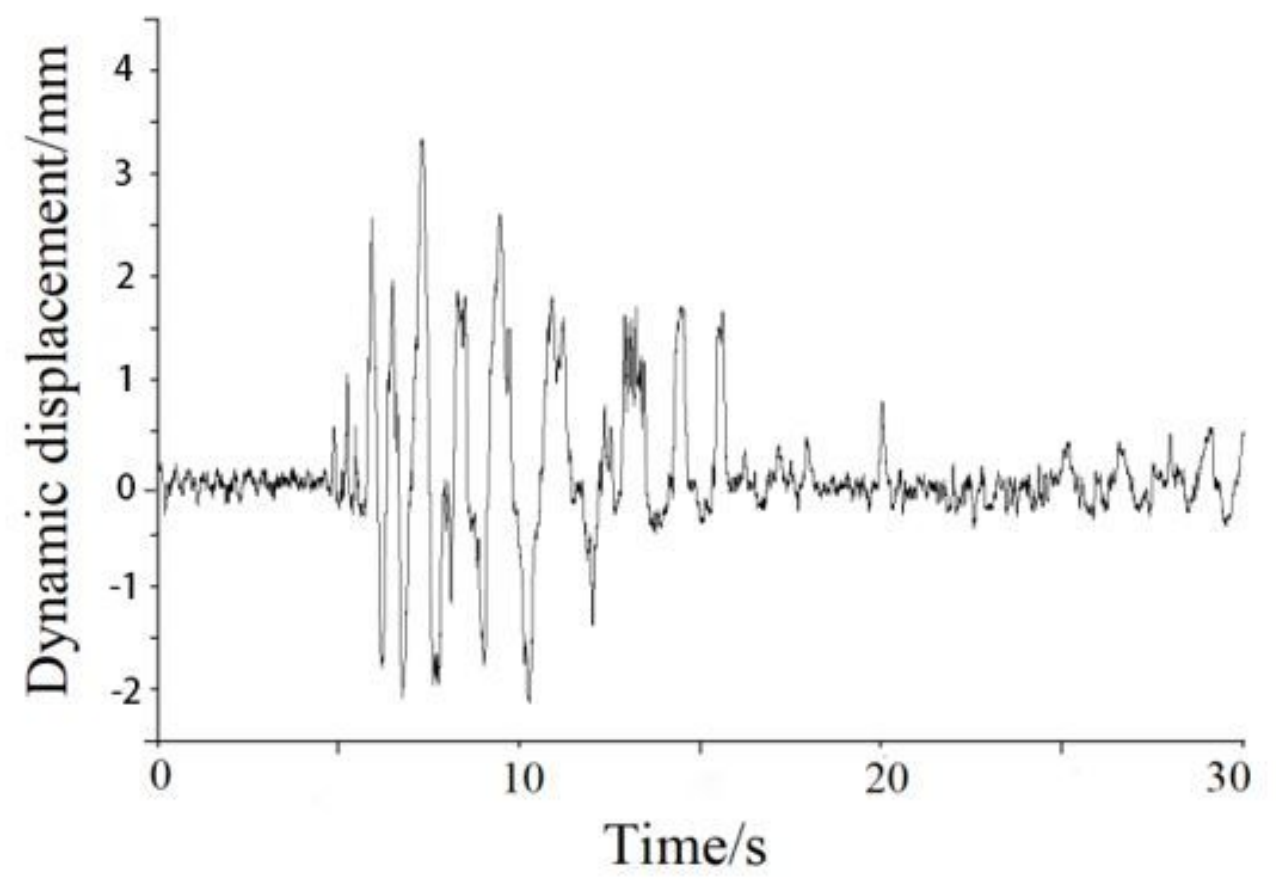

(b) WC-xz

Figure 15

Vertical displacement response time-history curves of point DZ5 


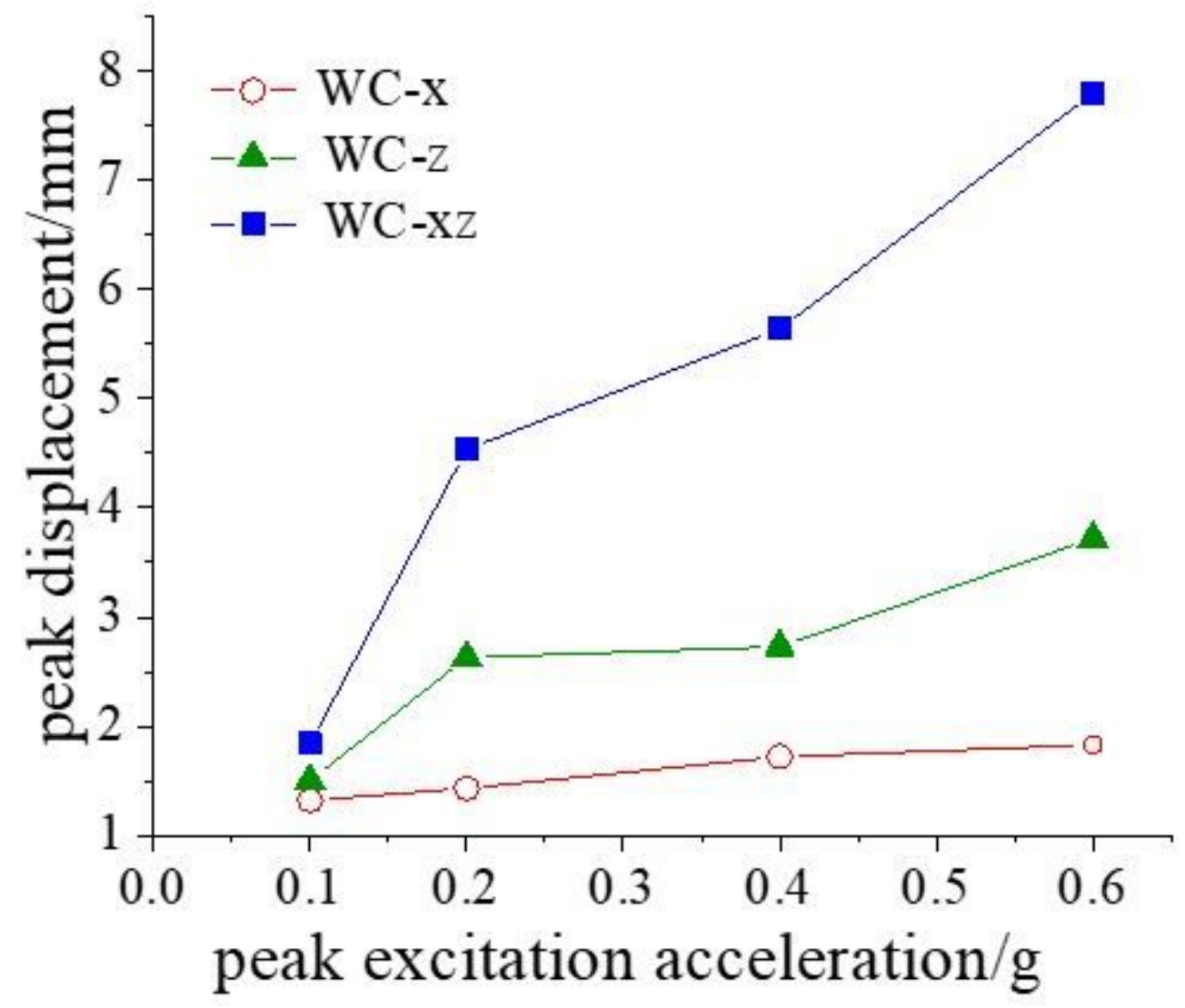

Figure 16

Relation between vertical displacement of point DZ5 with and peak load 


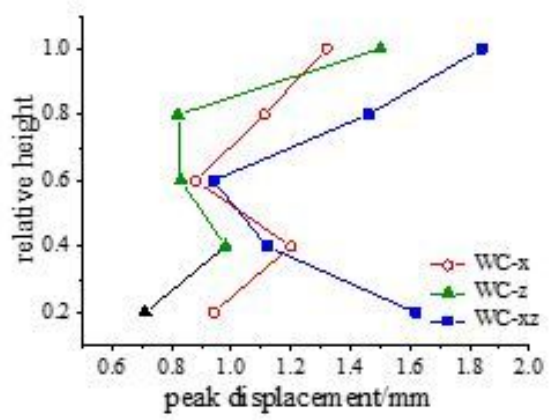

(a) $0.1 \mathrm{~g}$

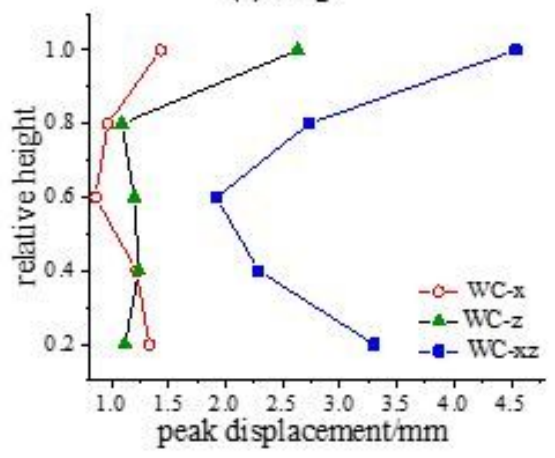

(b) $0.2 \mathrm{~g}$

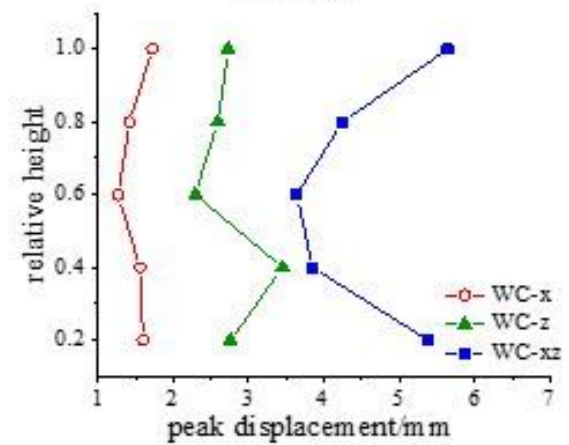

(c) $0.4 \mathrm{~g}$

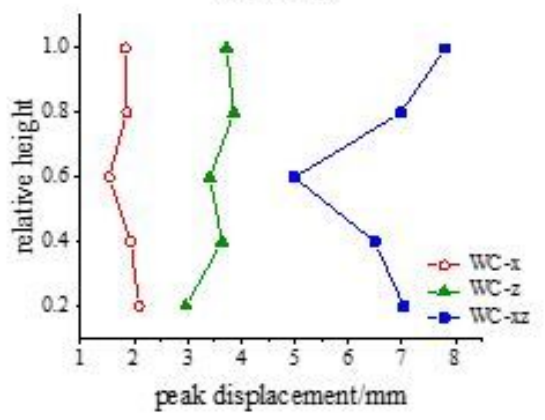

(d) $0.6 \mathrm{~g}$

Figure 17

Regular of vertical dynamic displacement peak response varies with height of slope

\section{Supplementary Files}

This is a list of supplementary files associated with this preprint. Click to download. 
- Table1.jpg

- Table2.jpg

- Table3.jpg

- Table4.jpg 